\title{
Ultrafast Fiber Lasers with Low-Dimensional Saturable Absorbers: Status and Prospects
}

\author{
Pulak Chandra Debnath ${ }^{1,2}$ (D) and Dong-Il Yeom ${ }^{1,2, *}$ \\ 1 Department of Energy Systems Research, Ajou University, 206 Worldcup-ro, Yeongtong-gu, \\ Suwon 16499, Korea; pcd2k1@ajou.ac.kr \\ 2 Department of Physics, Ajou University, 206 Worldcup-ro, Yeongtong-gu, Suwon 16499, Korea \\ * Correspondence: diyeom@ajou.ac.kr; Tel.: +82-31-219-1937
}

Citation: Debnath, P.C.; Yeom, D.-I.

Ultrafast Fiber Lasers with

Low-Dimensional Saturable Absorbers: Status and Prospects. Sensors 2021, 21, 3676. https:// doi.org/10.3390/s21113676

Academic Editors: Min Yong Jeon and Krzysztof Abramski

Received: 13 April 2021

Accepted: 16 May 2021

Published: 25 May 2021

Publisher's Note: MDPI stays neutral with regard to jurisdictional claims in published maps and institutional affiliations.

Copyright: (c) 2021 by the authors. Licensee MDPI, Basel, Switzerland. This article is an open access article distributed under the terms and conditions of the Creative Commons Attribution (CC BY) license (https:/ / creativecommons.org/licenses/by/ $4.0 /)$.

\begin{abstract}
Wide-spectral saturable absorption (SA) in low-dimensional (LD) nanomaterials such as zero-, one-, and two-dimensional materials has been proven experimentally with outstanding results, including low saturation intensity, deep modulation depth, and fast carrier recovery time. LD nanomaterials can therefore be used as SAs for mode-locking or Q-switching to generate ultrafast fiber laser pulses with a high repetition rate and short duration in the visible, near-infrared, and midinfrared wavelength regions. Here, we review the recent development of emerging LD nanomaterials as SAs for ultrafast mode-locked fiber laser applications in different dispersion regimes such as anomalous and normal dispersion regimes of the laser cavity operating in the near-infrared region, especially at $\sim 1550 \mathrm{~nm}$. The preparation methods, nonlinear optical properties of LD SAs, and various integration schemes for incorporating LD SAs into fiber laser systems are introduced. In addition to these, externally (electrically or optically) controlled pulsed fiber laser behavior and other characteristics of various LD SAs are summarized. Finally, the perspectives and challenges facing LD SA-based mode-locked ultrafast fiber lasers are highlighted.
\end{abstract}

Keywords: ultrafast fiber laser; saturable absorber; low-dimensional materials; optically/electrically controlled fiber lasers

\section{Introduction}

Ultrafast lasers have been proven as one of the most effective tools for a wide variety of applications in ultra-precision manufacturing, strong-field physics, nonlinear optics, medical diagnosis, astronomical detection, precision measurement, and fundamental scientific research because of their extremely narrow (femtosecond scale) pulse duration and large peak-power [1-6]. Among ultrafast lasers, the passively mode-locked ultrafast fiber laser (MLFL) based on a saturable absorber (SA) has also emerged as one of the most powerful strategies to develop ultrashort pulses ( $<100 \mathrm{fs}$ ) because of their benefits of high beam quality, low cost, efficient structure, alignment-free compact design, and excellent compatibility [6-9]. Passive mode-locking is a technique that creates a preferred environment for pulsed operation of a laser, effectively employing nonlinear polarization rotation (NPR), nonlinear amplifying loop mirror (NALM), and SA techniques [10-13]. In particular, the advancement of SA design is principally based on the evolution of materials having SA behaviors. In the recent past, the most extensively used form of SAs includes the semiconducting saturable absorber mirror (SESAM), a semiconducting quantum well structure prepared by a deposition method named molecular beam epitaxy (MBE) [14-19]. Modulation depth, SA coefficient, saturation fluence, and recovery time are some of the distinguishing characteristics of a SESAM, determined by adjusting the SESAM's structure. The high stability of the SESAM turns it into one of the significant choices as SAs. However, several detrimental features, including prolonged recovery time ( $\sim$ pico-second level), ultra-narrow working wavelength range, low damage threshold, complicated fabrication process, and high cost of SESAM, have guided the scientific community to find new SA 
materials which can replace SESAM quantum well. The first condition as alternative SA material is to exhibit a nonlinear absorption behavior such that the optical transmittance efficiently increases as the input laser power increases. Other requirements include a high damage threshold, wide operating range, fast recovery time, low cost, and reduced mode-locking threshold, which are vital for the additional advancement of mode-locked ultrafast fiber lasers.

Due to the optical nonlinearity of low-dimensional (LD) materials-based SAs, they are able to modulate and control the circulating light wave periodically in the laser cavity, which results in many longitudinal modes to phase oscillation through ultrafast carrier excitation and the recombination process, thus generating regular ultrashort pulse trains in the time scale. Pauli-blocking plays a critical role in an SA, which reduces the light absorption in the SA instantaneously if a large number of electrons are excited from the lower energy level of the SA to the upper energy level by the incidence of larger light fluence [6,20-22]. So far, the emergence of low-dimensional (LD) SA materials, including two-dimensional (2D), one dimensional(1D), and zero-dimensional (0D) materials such as graphene, carbon nanotubes (CNTs), quantum dots, respectively with various advantages over SESAM, provides a new prospect for the development of pulsed fiber lasers because of their distinct structure and physical properties [20-36]. They exhibit divergent physical behaviors varying from semiconductor to insulator and metal to semimetal [37-45]. 2D materials, which are mostly studied and investigated among three types of LD materials, have wide-ranging applications in optics, involving ultrafast fiber lasers as well as modulation, generation, propagation, and detection of light [46-53], have been employed to develop integrated photonic circuits.

2D material belongs to the atomic layer material, which can be a monolayer or multiplelayer thick. 2D materials have solid covalent bonding in a layer and weak interlayer van der Waals force. The electrons' dynamic is limited in the 2D structure if there is no interference of interlayer interaction, which provides 2D materials with numerous novel optical and electrical characteristics [53-55]. Graphene is the earliest monoatomic 2D layer material revealed, with remarkable optical, electrical, mechanical, and thermal behaviors [40-45]. Following 2D graphene, black phosphorus (BP), transition metal dichalcogenides (TMDs), topological insulators (TIs), perovskite and MXene, and other divergent 2D materials were investigated [8,9,56-58]. Moreover, the development of 1D materials such as carbon nanotubes (CNTs) and OD materials such as quantum dots (QDs) has also made numerous, excellent accomplishments in the development of mode-locked pulsed ultrafast fiber lasers (Figure 1) [22-24,28,59-64]. Since the CNT and graphene were firstly suggested in 2004 and 2009 as an optical SA for mode-locked ultrafast fiber lasers, respectively [21,22], many other LD materials other than graphene, comprising TMDs, TIs, black phosphorus, bismuthine, MXenes, and metal-organic frameworks, quantum dots have been consecutively investigated, implying the significant growth of new SAs based on LD for ultrafast fiber lasers $[8,35,58,65]$. In addition to these, externally tunable in-line nonlinear LD SAs, where the fiber laser operation can be tuned from continuous wave, through Q-switched to passively mode-locked regime employing electrical gating or external optical bias, have also been demonstrated using various LD SAs [25-27,66-68].

Here, in this review, we study the basic characteristics, renowned synthesis methods of the most widely studied LD materials, and fabrication methods for SA devices comprising various coupling techniques to incorporate LD SAs into fiber systems in brief. Afterward, we mainly focus on the advancement in mode-locked (ML) ultrafast fiber lasers based on various LD SAs (especially 2D and 1D) operating in different dispersion regimes at telecommunication wavelengths near $\sim 1550 \mathrm{~nm}$. In addition, we focus on the recent development of externally controlled fiber lasers based on various LD SAs, which operate in several operating regimes such as QS, QS-ML, and ML depending on the external electrical or optical bias to the SA. In the end, we discuss several prospects about the perspectives and potential advancements of ultrafast pulsed fiber lasers based on LD SA materials. 


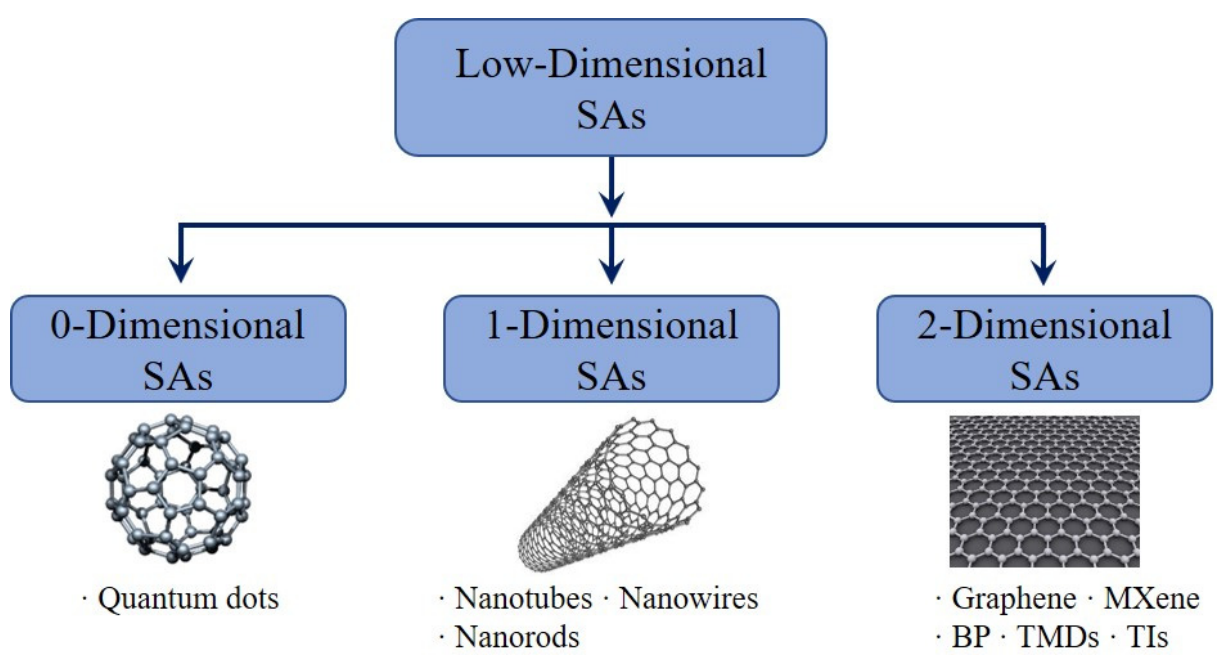

Figure 1. Low-dimensional SAs classification featured as $0 \mathrm{D}, 1 \mathrm{D}$ and $2 \mathrm{D}$ structure varieties. [Images are publicly available online].

\section{Properties/Characteristics of LD Materials}

\subsection{D Materials}

2D materials, in the area of ultrafast nonlinear optics and photonics, are distinguished by their ultrafast recovery, wideband nonlinear saturable absorptions, significant nonlinear refractive indices, and capability as superior mode-lockers for ultrafast fiber lasers [69-76]; what follows is a brief outline of atomic and bandgap structures, and recovery times in 2D materials. Figure 2 illustrates a detailed contrast among the discovered various 2D materials in the family. In this part of the review, fundamental characteristics of related various 2D materials and their incorporation techniques in fiber optic systems are discussed.

\subsubsection{Graphene}

Graphene, an atomic layered $\mathrm{sp}^{2}$-bonded carbon atom arranged in a honeycomb lattice [42,45], is considered as the pioneer of all 2D materials available afterward (Figure 2a), expediting huge prospectives for SA in the research field of ultrafast fiber lasers. Monolayer graphene is estimated to absorb a $2.3 \%$ incident light infrared (IR) region owing to its gapless Dirac cone structure $[40,44]$. Unique characteristics of graphene, such as ultrashort recovery time $(<200 \mathrm{fs})$, low saturable absorption $\left(\sim 10 \mathrm{MW} / \mathrm{cm}^{2}[77]\right)$, great relative modulation depth ( $>60 \%$ per layer [21]), and wavelength-independent operation (ranging from the visible to the terahertz), make it special and allow it to perform efficiently as an SA to build wideband mode-locked ultrafast fiber laser pulses.

\subsubsection{Transition Metal Dichalcogenides (TMDs)}

TMDs with the chemical formula $\mathrm{MX}_{2}$, where $\mathrm{M}$ refers to a transition metal (e.g., Mo, $\mathrm{Nb}, \mathrm{Ti}, \mathrm{W}$ ) and $X$ refers to a chalcogen (e.g., $\mathrm{S}$, Se, or Te), are a group $>40$ various semiconductors [78,79]. A TMD monolayer is displayed as a layered structure like graphene, where the single transition metal layer is sandwiched in between two chalcogen layers. TMD exhibits an energy bandgap ranging from 1 to $2.5 \mathrm{eV}$ as a group of semiconductors depending on different chemical compositions (Figure 2b). Surprisingly, incident photon energy on TMDs is considerably lower than their normal bandgaps, undergoing significant absorptions due to the carrier excitation within sub-bandgaps formed by the pristine edge states of TMDs $[80,81]$. In the meantime, TMDs exhibit ultrashort recovery times in the picosecond scale, useful in the field of ultrafast light modulation and ultrafast fiber lasers. For example, $\mathrm{MoTe}_{2}, \mathrm{MoS}_{2}, \mathrm{WS}_{2}$, and $\mathrm{WSe}_{2}$ have been extensively studied and investigated to generate ultrafast fiber lasers in 1.5 and $2 \mu \mathrm{m}$ wavelength regimes. 
(a)

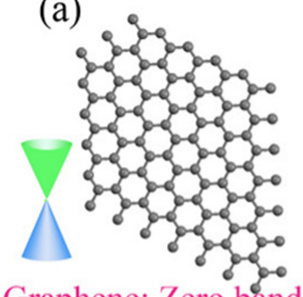

Graphene: Zero bandgap (b)

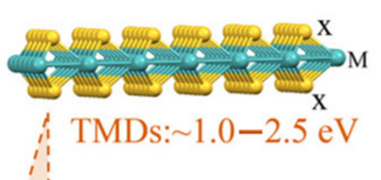

(c)

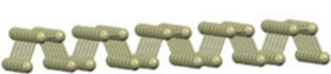

(d)
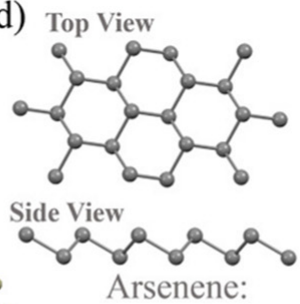

Arsenene:

Phosphorene: $~ 0.3-2 \mathrm{eV}$ Zero bandgap $-2.49 \mathrm{eV}$ (e)

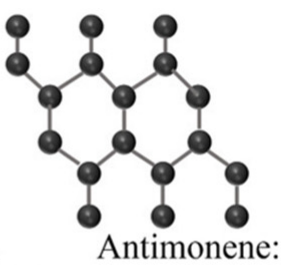

Zero bandgap $-2.28 \mathrm{eV}$

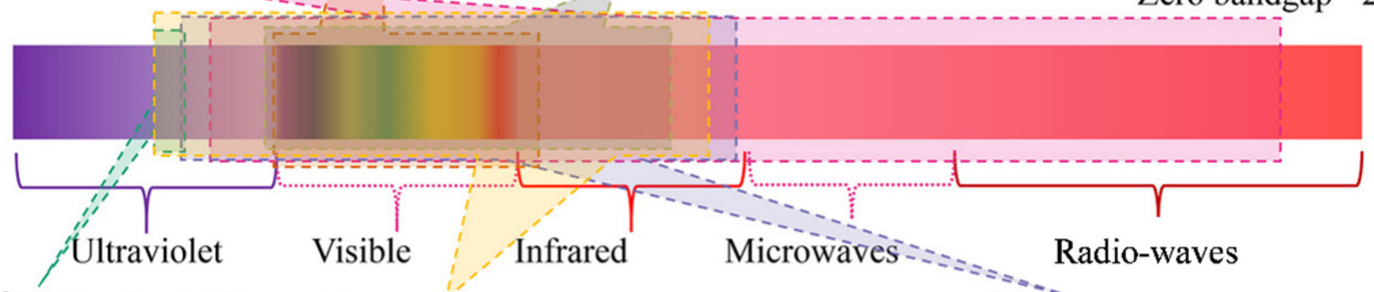

(f) $\mathrm{BN}: \sim 5-6 \mathrm{eV}$

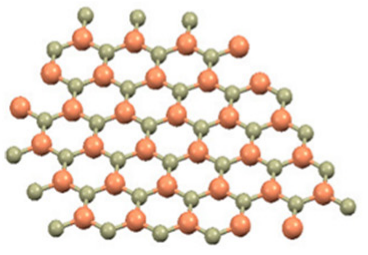

(g) MXene, $\mathrm{Ti}_{3} \mathrm{C}_{2} \mathrm{~T}$

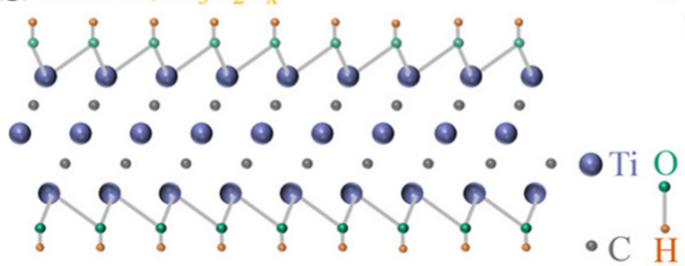

(h) Bismuthene: $\sim 0.28 \mathrm{eV}$

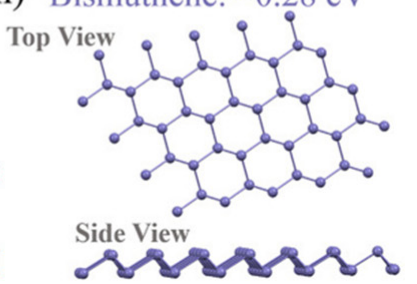

Figure 2. The atomic structure and spectral region of 2D materials. The atomic structure and spectral region of 2D materials such as graphene (a), TMDs (b), phosphorene (c), arsenene (d), antimonene (e), bismuthine (f), MXene (g), and BN (h). Reproduced with permission [82]. Copyright 2019, Wiley-VCH.

\subsubsection{Black Phosphorus (BP)}

$\mathrm{BP}$ is an allotrope of phosphorus and featured as thermodynamically stable at ambient temperature, also called phosphorene for its monolayer case (Figure 2c) $[83,84]$. BP is formed as a ring structure linked by six phosphorus atoms as with graphene, where each atom is linked to three neighboring phosphorus atoms. Unlike the graphene structure, the structure of BP is puckered, which breaks the symmetry and results in an angledependent optical nonlinearity [85]. BP is featured as a direct bandgap semiconductor that is tunable depending on the number of layers (thickness). The bandgap in BP is ranged from $0.35 \mathrm{eV}$ for a bulk case to $2 \mathrm{eV}$ for monolayer $\mathrm{BP}$, which revealed its wideband nonlinear optical response in the MIR regime [86,87], and extensive investigation for ultrafast fiber lasers $[24,88]$. It has been exhibited that when a BP nanosheet was excited by various wavelength light with photon energies ranging from 1.55 to $0.61 \mathrm{eV}$, the recovery time depending on the wavelength was varied from 0.36 to $1.36 \mathrm{ps}$ [89]. At room temperature, $\mathrm{BP}$ exposed to air in ambient conditions is unstable and degrades its physical properties, requiring high-quality passivation to improve its stability on a long-term basis [90].

\subsubsection{Topological Insulators (TIs)}

TIs are identified as novel 2D material along with other 2D materials having topological order protected by nontrivial symmetry, which acts as insulators in their inner portion, but gapless conducting states appear on its surfaces [91-93]. TIs exhibit effective wideband nonlinear optical responses, like graphene, from the visible to the mid-IR owing to their small indirect bulk bandgap of $0.2-0.3 \mathrm{eV}$. The phonon-induced carriers' lifetime of TIs is as short as several picoseconds, revealing them to be used for ultrafast fiber laser and nonlinear optical modulators. Among the various TIs, $\mathrm{Bi}_{2} \mathrm{Te}_{3}, \mathrm{Bi}_{2} \mathrm{Se}_{3}$, and $\mathrm{Sb}_{2} \mathrm{Te}_{3}$ are the most-used TIs as SAs. 


\subsubsection{MXenes}

MXenes categorized as a new class of 2D transition metal nitrides, carbonitrides, or carbides, with the composition of $\mathrm{M}_{\mathrm{n} 1} \mathrm{X}_{\mathrm{n}} \mathrm{T}_{\mathrm{x}} \mathrm{n}$, where $\mathrm{M}$ refers to transition metals (Ti, $\mathrm{Sc}, \mathrm{Hf}, \mathrm{Zr}, \mathrm{Nb}, \mathrm{V}, \mathrm{Cr}, \mathrm{Mo}$, Ta, etc.), $\mathrm{X}$ stands for nitride and/or carbide, and $\mathrm{T}_{\mathrm{x}}$ is surface terminations $\left(\mathrm{O}, \mathrm{OH}, \mathrm{F}\right.$, etc.) $[94,95]$. Few-layer $\mathrm{Ti}_{3} \mathrm{C}_{2} \mathrm{~T}_{\mathrm{x}}$ exhibits an indirect energy bandgap lower than $0.2 \mathrm{eV}$ and reduced absorption of around 1\%/nm (Figure 2g). 2D MXene materials are usually periodically stacked by means of van der Waals interaction in which no internal termination occurs, a similar feature seen in phosphorene, graphene, and TMDs. In the latest work, it was observed that stacked MXene comprises a set of monolayer MXene in it without any significant disorder [33], implying the possibility of using MXenes as an SA to generate ultrafast fiber lasers, which avoids the deleterious methods of monolayer dispersion.

\subsubsection{Bismuthine}

Bismuthine has drawn immense attention in the scientific community, owing to its unique electronic and mechanical characteristics, along with its excellent stability $[37,96]$. In the latest report, the tunable optical bandgap depending on the layer number varied from nearly 0 to $0.55 \mathrm{eV}$ (Figure 2h) in beta-bismuthine, which reveals bismuthine as an effective wideband nonlinear optical material from the terahertz regions to the near-IR [97]. Comparably shorter recovery time of $2.8 \mathrm{ps}$ in monolayer bismuthine also implies that bismuthine can be a potential candidate as an SA for ultrafast fiber laser applications.

\subsubsection{Other 2D Materials}

The 2D materials mentioned above display distinctive yet complementary characteristics and, therefore, new opportunities for optical applications in ultrafast fiber lasers [98-100]. However, the SA technology required for standard fiber laser operation is always anticipated as perfect as it is theoretically attributed with superior optical properties including ultrashort carrier lifetimes, elevated modulation depths, and damage thresholds. Therefore, it is obvious that exploring novel 2D materials as SA is continuous since it was first implemented. In addition, the controllability of key features in current $2 \mathrm{D}$ SAs and engineering in the laser cavity with tunable behavior of SAs also offers more functionalities in the development of controllable ultrafast fiber lasers [25-27,66,68,101]. Combining two or more similar or different 2D materials and building van der Waals heterostructures prospects towards developing multi-functional, high efficiency, broadband controllable photonic devices [102,103]. Recently, several ultrafast fiber lasers mode-locked by heterostructure SAs have been reported $[104,105]$.

\section{2. $1 D$ Materials \\ Carbon Nanotubes (CNTs)}

Carbon nanotubes, a unified cylindrical, 1D nanocrystalline graphite material with a high aspect ratio, include a diameter varying from a few to several hundred nanometers and length of up to centimeters. According to the number of tube walls, CNTs can be divided into many types: single-walled CNTs (SWCNTs), double-walled CNTs, and multi-walled CNTs. The chiral properties of carbon tubes lead to different applications of metallic and semiconducting carbon tubes. The carbon tube of the semiconductor type has an obvious bandgap, while the band of the metal type is continuous. CNTs possess multiple excellent properties and advantages that are well fitted with the requirements of a good SA. The measured third-order nonlinear polarizability by pump-probe spectroscopy is $10^{-7}-10^{-10}$ esu $\left(1 \mathrm{esu}=1.11 \times 10^{-9} \mathrm{~m}^{2} \mathrm{~V}^{-2}\right)$. The recovery time was measured to be composed of a fast intraband carrier relaxation time of $0.3-1.2 \mathrm{ps}$ and a slow recombination process of 5-20 ps [106]. Moreover, the superior thermal conductivities as high as $5000 \mathrm{~W} \mathrm{~m}^{-1}$ guarantee intrinsic high-power handling. A highly developed growth process significantly lessens the price of raw materials as well as the research cost. More notably, the expansion of CNT SAs over the past 15 years simplified the direction of all-fiber integration 
configuration, and extensive investigations have validated its operation in a broadband range, which is an underlying disadvantage of industrial SESAMs. Therefore, CNT SAs are a trustworthy candidate to perform as a promising replacement to SESAMs in the future.

\section{Synthesis of LD SA and Device Fabrication}

\subsection{Synthesis Techniques}

In the past decade, several synthesis techniques have been successfully established to prepare the LD materials introduced in the previous section. The most common synthesis methods for LD materials are categorized into two types: top-down and bottom-up methods. To briefly review, a few standard methods from these types are discussed. The top-down exfoliation methods comprise liquid-phase exfoliation (LPE), mechanical exfoliation (ME), laser thinning, and chemical exfoliation, where single-layer or multiple-layer 2D nanosheets are separated from bulk materials by violating the van der Waals force between layers [9]. Bottom-up methods include pulsed laser deposition (PLD) and chemical vapor deposition (CVD), where high-quality 2D materials in atomic layer scale are effectively synthesized by explicitly adjusting the chemical reactions among solid precursors. Most common and widely applied synthesis and preparation methods for 2D SAs to realize mode-locked fiber lasers will be discussed in brief.

\subsubsection{Mechanical Exfoliation (ME)}

The ME technique is commonly used in the manufacturing of atomically and few layers thick sheets of 2D layered inorganic materials [44,107-110]. Researchers can acquire high-quality 2D mono- and few-layer materials by resolving the van der Waals force and splitting layers away from bulk materials. This method was first used in the discovery of 2D graphene from graphite flakes in 2004 by Geim and Novoselov [44] owing to its flexibility and potential to manufacture few-layer materials with outstanding qualities. Compared to the bulk materials, single-layered or multi-layered 2D materials are highly comprehensive and have negligible defects, making them ideal for basic scientific study. Although this method is convenient, fast, and cost-effective, it does have some drawbacks. Since large-area single-layer 2D materials synthesis using this method is difficult, it is only appropriate for fundamental research in a laboratory. Many studies have demonstrated ME using scotch tape to synthesize other 2D materials. This procedure is often used to obtain monolayer BP. Zenghui Wang et al. employed key strategies specifically designed to expedite the transfer of BP after exfoliation to reduce the material's exposure to the ambient conditions [111].

\subsubsection{Liquid Phase Exfoliation (LPE)}

Liquid phase exfoliation with a high yield has become a viable alternative to mechanical exfoliation [50,112], where large numbers of dispersed 2D layers are exfoliated from its bulk (layered compound) state in liquids. There are four LPE approaches mostly used to eliminating interlayer forces: (i) oxidation followed by ultrasonication, (ii) ion intercalation, (iii) ion exchange, and (iv) sonication-assisted exfoliation. In the oxidation method, layered 2D crystals with low reductive potential are exfoliated by oxidation and subsequent dispersion and ultrasonication in suitable solvents. In ion intercalation, the interlayer gap is expanded by embedding organic or ionic materials as intercalants, such as $n$-butyllithium or IBr in liquids, which disrupt the interlayer adhesion force between the 2D layers in bulk. In ion-exchange methods, layered compounds contain ions between the layers so as to balance the surface charge on the layers. These ions are exchanged in a liquid environment for other larger ions, leading to substantial swelling in layered compounds, and subsequent agitation results in an exfoliated dispersion. The other method is to create microbubbles and pressures between layers of bulk materials directly using high-intensity ultrasonics. However, these approaches can effectively modify the material's composition in liquids, and the quality must be enhanced further. 


\subsubsection{Chemical Vapor Deposition (CVD)}

The uncontrollable scale and random thickness of few-layered 2D materials acquired using the ME or LPE techniques are counterproductive to the efficiency of an SA $[113,114]$. CVD is an essential bottom-up approach for synthesizing comparatively large area 2D materials with scalability. In 2009, the CVD technique was first employed to synthesize graphene on a copper substrate with a large area (centimeter scale) and high uniformity [115]. Following this synthesis, numerous 2D materials including TIs and TMDs were synthesized employing the CVD method. Few-layer $\mathrm{WSe}_{2}$ with a large area and improved quality were synthesized by CVD to be employed as SA in the generation of ultrafast fiber laser, reported by W. Liu et al. as shown in Figure 3 [116]. One of the key features of the CVD technique is its functionality to adjust the number of layers in 2D materials, which elevates the modulation depth of 2D SAs. Nevertheless, this method undergoes deleterious transfer steps from the grown substrate to the fiber system to build the SA device, making this technique complicated to realize cost-effective devices [21,116,117]. To solve these issues, direct synthesis methods have been reported for graphene to build nonlinear optical devices including SA devices [32,101,118-120].

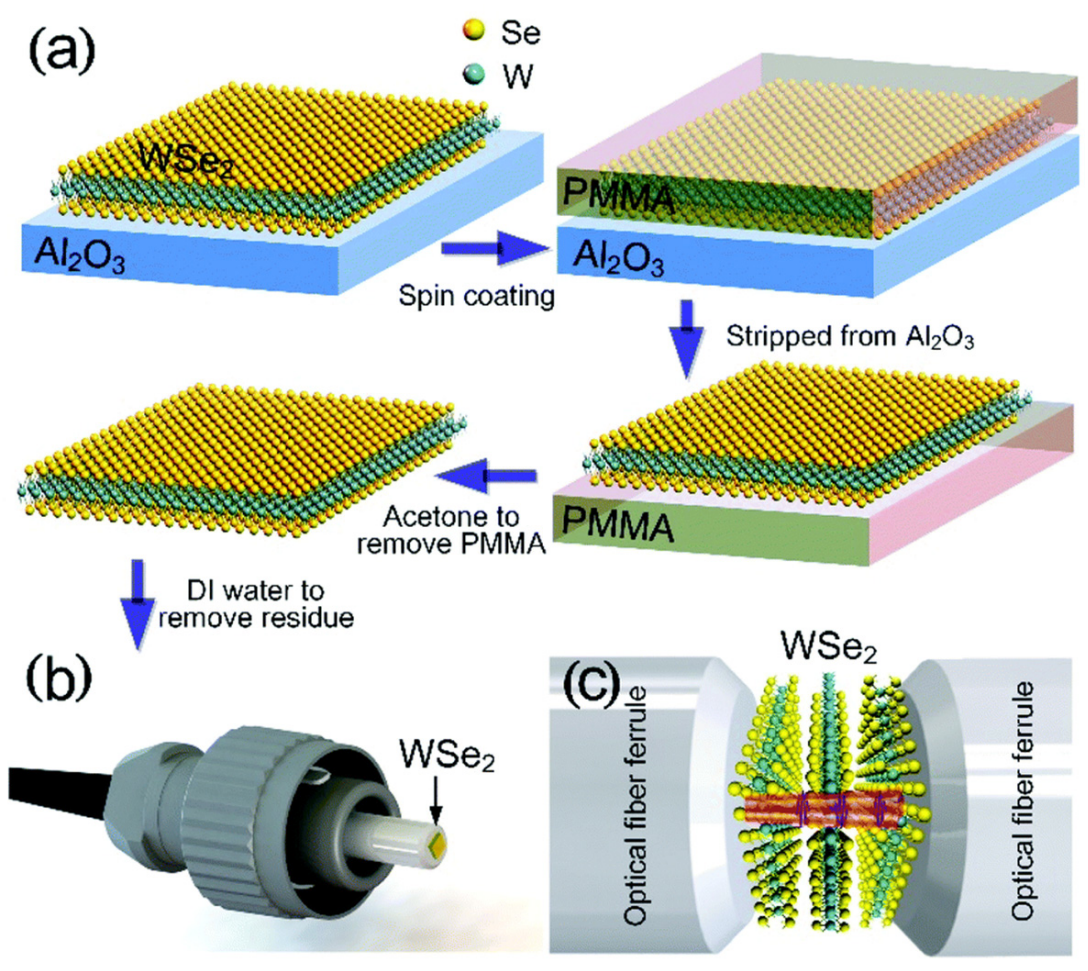

Figure 3. Graphic illustration of the preparation of the $\mathrm{WSe}_{2}$-based SA by the CVD method. (a) The transfer scheme of $\mathrm{WSe}_{2}$ films. (b) optical image of $\mathrm{WSe}_{2}$ films transferred onto the fiber ferrule end facet. (c) schematic presentation of the few-layer $\mathrm{WSe}_{2}$ and light interaction. Reproduced with permission [116]. Copyright 2018, RSC.

\subsection{LD SAs Integration with Optical Fiber}

LD materials should be transferred, synthesized, or directly deposited onto optical fibers to build in-line SA devices. Additionally, a significant interaction of LD material with guided light is required for the stable operation of all-fiber mode-locked ultrafast fiber lasers. Usually, these coupling techniques are variously beneficial for different fiber laser schemes. For LD SA-based fiber lasers, the incorporation of SA must be done with the optical fiber or its component. Figure 4 illustrates a variety of mostly utilized fiber coupling methods which are classified into two cases: transmission coupling and evanescent-field coupling. 


\subsubsection{Direct Coupling}

Direct coupling is the most widespread method to realize SA devices, where SA is sandwiched directly between two fiber end facets, as illustrated in Figure 4a. Various LD materials including mechanically exfoliated graphene, CVD-grown graphene or TMDs, 1D $\mathrm{CNT}$, and MBE-grown TIs have been incorporated in fiber end facets using this method in the previous research [121]. Direct coupling facilitates the stable interaction between the guided laser signal and the SA, resulting in reliable mode-locking operation. Nevertheless, if the incident laser power is relatively high, the direct interaction scheme often leads to significant damage to the SA. Thus, a direct coupling scheme with sandwiched SA materials is generally suitable for mode-locked ultrafast fiber lasers operating at low average power.

\subsubsection{Evanescent-Field Coupling}

To reduce the damage threshold of fiber SAs, a widely used alternative technique called evanescent-field coupling was introduced to incorporate LD SAs onto a tapered fiber and a D-shaped fiber (also called side-polished fiber, SPF) as shown in Figure 4c,d. In 2007, Yamashita et al. for the first time introduced evanescent field coupling of CNTs on SPF and tapered fiber [122,123]. The evanescent field of guided light through the fiber in this scheme interacts with LD SA on the fiber surface. As shown in Figure 4b, SA materials can be filled into a hollow photonic crystal fiber (PCF) and a hollow core fiber (HCF), which are linked to the fiber laser cavity $[124,125]$. To achieve this, LD SA materials are initially dispersed in a solvent followed by the subsequent filling of SA dispersion into the hollow PCF and HCF. Then the SA-filled PCF or HCF is dried and connected to the fiber laser ring cavity [125]. However, the core size of PCFs being in the $\mu \mathrm{m}$ range, it is challenging to dry the solvent completely inside the core, resulting in elevated insertion losses, hence the unstable performance of ultrafast fiber lasers.

(a)
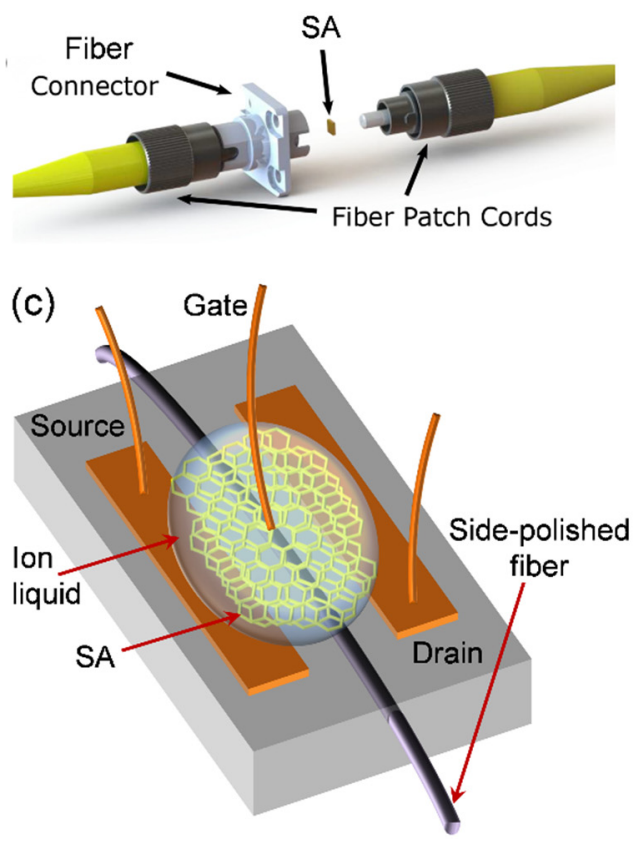

(b)

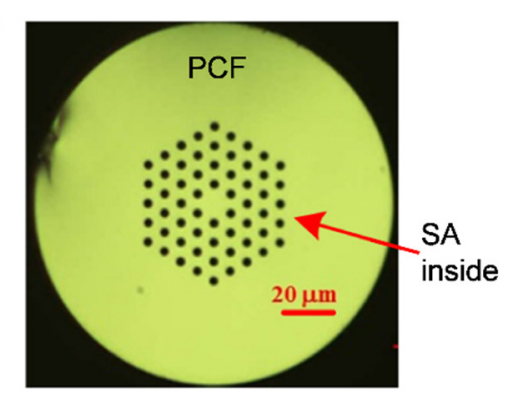

(d)

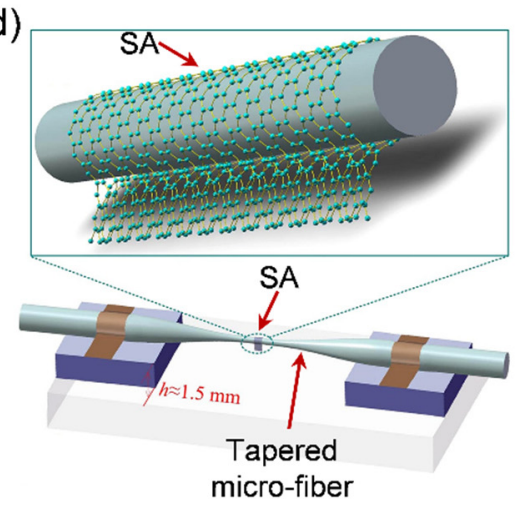

Figure 4. Various schemes for incorporating LD SAs in optical fiber. (a) SA sandwiched between two fiber connectors. Reproduced with permission [126]. Copyright 2015, The Optical Society of America. (b) LD SA injected inside a hollow photonic crystal fiber (PCFs). Reproduced with permission [125]. Copyright 2013, The Optical Society of America. (c) LD SAs transferred onto SPF surface. (d) depositing SAs around tapered micro-fiber. Reproduced with permission [127]. Copyright 2016, Springer Nature. 
After incorporation of LD SA in the fiber system, the SA module must be examined to ensure the successful incorporation was occurred or not. The most common technique to characterize the SA module is nonlinear transmission to analyze the modulation depth, saturation fluence, and non-saturable loss of the SAs in a fiber setup [20,21,25].

\section{Ultrafast Fiber Laser Based on LD SA}

In the field of SA-based fiber lasers, mode-locking and Q-switching are two key techniques to generate ultrashort pulses. Both the techniques are useful and selective for various applications depending on their different advantages. Q-switched lasers are mostly utilized in laser processing and military purposes owing to their high pulse energy. On the other hand, because of the ultrashort pulse duration in the femtosecond scale, mode-locked lasers are employed in the areas of nonlinear imaging, micromachining, and fundamental scientific research. Figure 5 shows a comparatively compact and convenient all-fiber laser ring cavity where the optical isolator, output coupler, and wavelength division multiplexer are combined in a hybrid component to reduce the size of the cavity [128]. Over the last decade, numerous LD SAs have been introduced following the invention of graphene and CNT as SA to build ultrafast fiber lasers using the typical fiber laser cavity mentioned above. A summary of various LD SA-based mode-locked Erbium-doped ultrafast fiber lasers' basic characteristics is provided in Table 1. In terms of the performance of these mode-locked lasers based on graphene, some exciting results have been obtained, including the minimum pulse width and maximum output power of $29 \mathrm{fs}$ [129] and $174 \mathrm{~mW}$ [130], respectively. For TIs, the corresponding figures were $128 \mathrm{fs}$ [131] and $75 \mathrm{~mW}$ [132], for TMDs they were $67 \mathrm{fs}$ [133] and $57 \mathrm{~mW}$ [134], and for BP they were $102 \mathrm{fs}$ [135] and $5.6 \mathrm{~mW}$ [114], respectively. Below we introduce the mode-locked ultrafast fiber laser based on several LD SAs and review the advancement of MLFL in terms of controllability in operation, performance, and application.

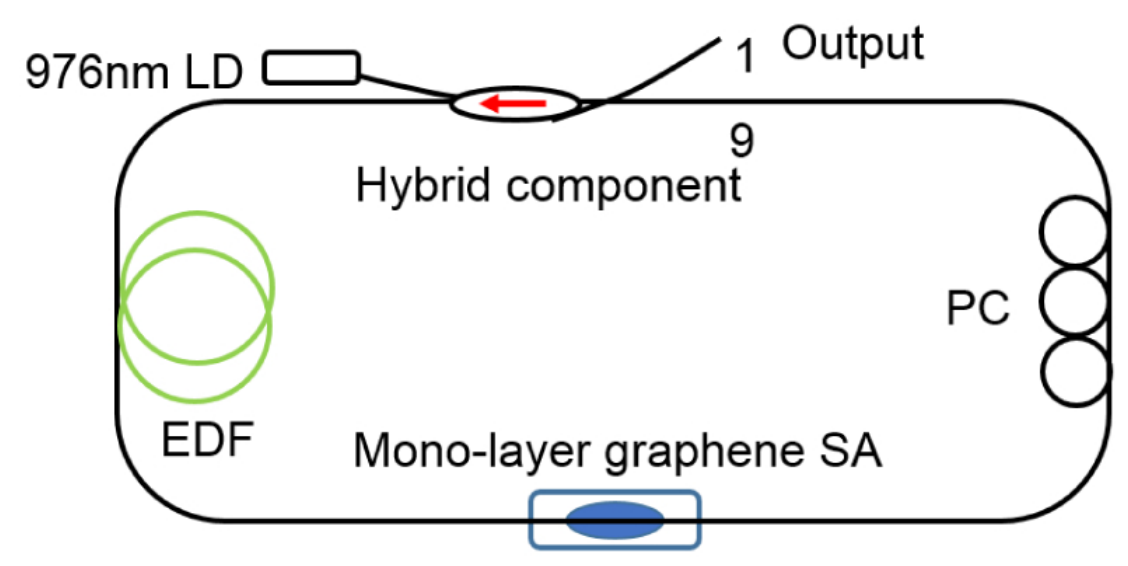

Figure 5. Schematic illustration Er-doped fiber laser ring-cavity comprising a single layer graphene SA on the SPF. LD: laser diode; EDF: erbium-doped fiber; PC: polarization controller; hybrid component: an integrated wavelength-division multiplexer and isolator. Reproduced with permission [128]. Copyright 2015, The Optical Society of America.

\subsection{Ultrafast Fiber Laser Based on Graphene SA}

After the discovery of graphene, it has been widely studied and investigated in various scientific research fields because of its distinctive nonlinear optical properties [31,54,136]. The features of broadband optical absorption, ultrafast carrier recovery, gapless band structure, and high damage threshold make graphene one of the leading SAs in the application of fiber laser lasers. First, the convergence of valence band and conduction band at the Dirac point of graphene denotes a gapless semi-metallic band, i.e., zero-bandgap structure, which results in graphene being conducive to wideband absorption. Secondly, the presence of an exclusive quantum tunneling effect in graphene carriers implies fast relaxation time and higher carrier. The relaxation time was investigated through pump-probe experiments 
in graphene by Bao et al., and the fast relaxation time of $150 \mathrm{fs}$ has been measured in the case of graphene [137]. They exhibited that, to shape ultrashort laser pulses in fs scale, the graphene with a fast relaxation time is more effective. Finally, graphene has a melting point of up to $4510 \mathrm{~K}$ [138]. In the experiment, a high damage threshold with graphene SA indicates an appropriate application of graphene SA in high-power lasers. To date, numerous studies and investigations with graphene in ultrafast fiber lasers have been performed. Bao et al. designed and created graphene SA devices for the first time. They investigated graphene SAs as nonlinear optical materials which were employed to generate stable mode-locked ultrafast Erbium-doped fiber laser (EDFL) with $3 \mathrm{~dB}$ bandwidth of $5 \mathrm{~nm}$ operating at $1565 \mathrm{~nm}$. Following this work, graphene SA-based MLFL has been a hot topic to investigate the various schemes and techniques for controllable MLFL based on graphene SA. In addition, Park et el. utilized the evanescent field coupling of monolayer graphene to produce graphene SA on SPF [128]. Through numerical study, they showed that a strong optical absorption of more than $90 \%$ can be achieved without significant scattering loss in a monolayer-graphene saturable absorber by employing an index-matched over-cladding structure on the graphene/SPF. By tuning the index of over-cladding, they effectively controlled and tuned the light coupling into the laser cavity, which results in significant control of the MLFL characteristics. Figure 6 shows the optical spectrum of the laser output, where the measured average output power was $5.41 \mathrm{~mW}$ at an applied pump power of $120 \mathrm{~mW}$. The typical spectral shape of an optical soliton was observed, where the measured spectral bandwidth was $8.6 \mathrm{~nm}$ at $1607.7 \mathrm{~nm}$. Assuming a soliton pulse, the pulse duration measured by an intensity autocorrelator was $377 \mathrm{fs}$, as shown in Figure 6b, the fundamental repetition rate was measured to be $37.72 \mathrm{MHz}$ (Figure 6c). The pulse width of the mode-locked laser reduced with the over-cladding index increased, where the measured pulse widths were 429,395 , and $377 \mathrm{fs}$ for the over-cladding indices of 1.426 , 1.434 , and 1.444 , respectively (Figure $6 \mathrm{~d}$ ).
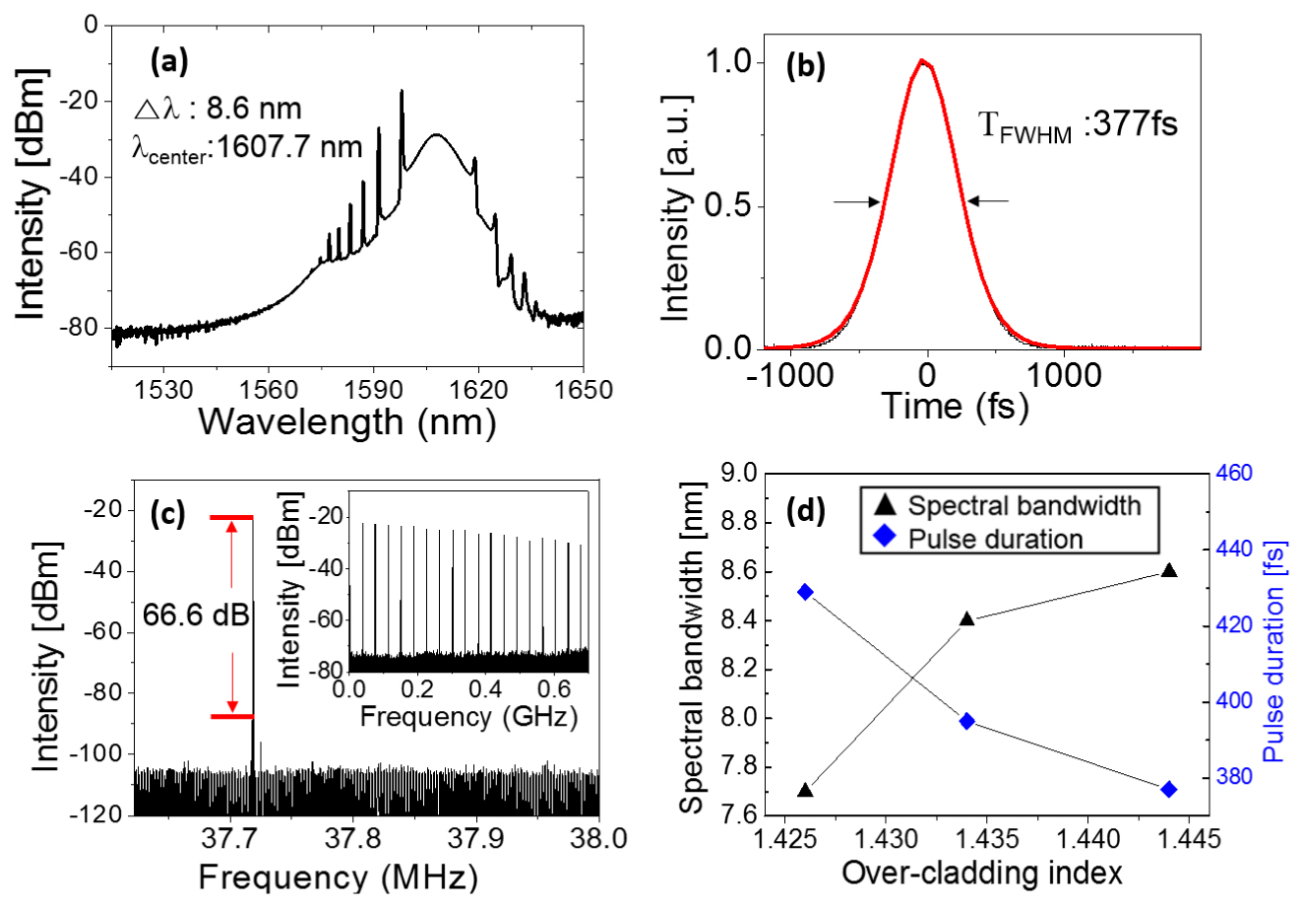

Figure 6. Mode-locked ultrafast fiber laser based on graphene SA (a) soliton pulse spectrum and (b) autocorrelation trace of the mode-locked pulse. (c) RF spectrum of the laser output pulse train (inset: RF spectrum viewed over a wide frequency range) and (d) 3-dB bandwidth and pulse width of the implemented laser as functions of the over-cladding index of the SA. Reproduced with permission [128]. Copyright 2015, The Optical Society of America. 
Table 1. Summary of the characteristics of various LD SA-based ultrafast fiber lasers operating at $\sim 1.55 \mu \mathrm{m}$.

\begin{tabular}{|c|c|c|c|c|c|c|c|}
\hline SA & $\begin{array}{c}\text { Center } \\
\text { Wavelength (nm) }\end{array}$ & $\begin{array}{c}3 \mathrm{~dB} \\
\text { Bandwidth (nm) }\end{array}$ & $\begin{array}{c}\text { Pulse } \\
\text { Duration (ps) }\end{array}$ & $\begin{array}{l}\text { Repetition } \\
\text { Rate (MHz) }\end{array}$ & $\begin{array}{c}\text { Output } \\
\text { Power (mW) }\end{array}$ & $\begin{array}{l}\text { Pulse Energy } \\
\text { (nJ) }\end{array}$ & Ref. \\
\hline \multirow{8}{*}{$\begin{array}{l}\text { Graphene } \\
\text { (2D) }\end{array}$} & 1559.12 & 6.16 & 0.432 & 25.67 & - & 0.09 & [139] \\
\hline & 1566 & 4.92 & 0.88 & 6.22 & - & - & [140] \\
\hline & 1555 & 6 & 0.59 & 45.88 & 0.91 & - & [141] \\
\hline & 1545 & 48 & 0.088 & 21.15 & 1.5 & 0.071 & [142] \\
\hline & 1553 & 3 & 1 & 8 & 1 & 0.125 & [143] \\
\hline & (CS)1565 & 7 & \multirow{2}{*}{13.8} & 25.8 & 0.7 & \multirow{3}{*}{10.2} & \\
\hline & (DS)1559 & 10.4 & & 16.99 & 174 & & [130] \\
\hline & 1607.7 & 7.7-8.6 & $0.37 \sim 0.429$ & 37.72 & 5.41 & & [128] \\
\hline \multirow{8}{*}{$\begin{array}{l}\text { CNT } \\
(1 \mathrm{D})\end{array}$} & 1547.5 & 0.3 & 22.73 & 10.61 & 11.21 & 1.057 & [144] \\
\hline & 1560.1 & 4.3 & 0.763 & 62.2 & 0.445 & 0.007 & [145] \\
\hline & 1555.1 & 3.9 & 0.85 & 10.89 & 3.19 & 0.29 & [146] \\
\hline & 1564.5 & 5 & 0.57 & 18.3 & 0.316 & $0.017 \mathrm{pJ}$ & [147] \\
\hline & 1563 & 12.1 & 12.7 & 9.8 & 335 & 34 & [60] \\
\hline & 1560 & 4.83 & 0.602 & 11.25 & 8.58 & 0.763 & [64] \\
\hline & 1560 & 4.33 & 22.2 & 0.51 & 4 & 0.18 & [61] \\
\hline & 1560 & 42 & 0.093 & 38.117 & 11.2 & 0.3 & [148] \\
\hline \multirow{4}{*}{$\begin{array}{l}\mathrm{BP} \\
(2 \mathrm{D})\end{array}$} & 1569.24 & 9.35 & 0.280 & 60.5 & - & - & [149] \\
\hline & 1566.5 & 3.39 & 0.94 & 4.96 & 5.6 & - & [114] \\
\hline & 1561.1 & 3.25 & 0.8 & 5.86 & 0.3 & 0.051 & [150] \\
\hline & 1555 & 40 & 0.102 & 23.9 & 1.7 & 0.071 & [135] \\
\hline \multirow{9}{*}{$\begin{array}{l}\mathrm{Bi}_{2} \mathrm{Se}_{3} \\
\quad(\mathrm{TI})\end{array}$} & 1557.5 & 4.3 & 0.66 & 12.5 & 1.8 & 0.144 & [30] \\
\hline & 1558.3 & & 3.01 & 5.1 & & & \\
\hline & 1557.4 & 0.9 & 3.42 & (HML)388 & - & - & [151] \\
\hline & 1559.4 & & 2.02 & (HML)239 & & & \\
\hline & 1600 & 7.9 & 0.36 & 35.45 & 0.86 & - & [152] \\
\hline & 1554.56 & 7.91 & 0.908 & (CS)20.27 & 5.5 & 0.27 & \\
\hline & 1559 & 26 & 7.564 & (DS)7.04 & 75 & 0.27 & {$[132]$} \\
\hline & 1562.4 & 4.28 & 0.630 & 23.3 & - & 0.0156 & [153] \\
\hline & 1557.908 & 0.342 & $7.78 \mathrm{~ns}$ & 1.71 & 82.6 & 48.3 & [154] \\
\hline \multirow{7}{*}{$\begin{array}{c}\mathrm{Bi}_{2} \mathrm{Te}_{3} \\
\text { (TI) }\end{array}$} & 1570 & $5.88 \sim 6.66$ & 0.403 & 28.5 & - & - & [155] \\
\hline & (DS)1560 & 5.6 & $2.7 \mathrm{~ns}$ & 1.7 & 32.9 & 19.3 & [156] \\
\hline & (CS)1558.5 & 0.95 & 1.22 & 4.88 & 5 & 1.02 & \\
\hline & (HML)1558.5 & 1.08 & 2.49 & $2.04 \mathrm{GHz}$ & 5.02 & - & {$[15 /]$} \\
\hline & 1547 & 4.63 & 0.6 & 15.11 & 0.8 & 0.0529 & [107] \\
\hline & 1558.459 & 1.696 & $3.22 \mathrm{~ns}$ & 1.704 & 40.37 & 23.9 & [158] \\
\hline & 1560.8 & 9.15 & 0.286 & 18.55 & 0.5 & 0.027 & [159] \\
\hline \multirow{11}{*}{$\begin{array}{l}\mathrm{MoS}_{2} \\
(\mathrm{TMD})\end{array}$} & 1570.1 & 2.7 & 1.36 & 5.924 & 3.5 & 0.59 & [29] \\
\hline & 1571.8 & 3.5 & 0.83 & 11.93 & 5.85 & 0.49 & [160] \\
\hline & 1574.6 & 9.5 & 0.79 & 29.5 & 4.13 & 0.14 & [161] \\
\hline & 1568 & 23.2 & 4.98 & (DS)26.02 & - & _- & \\
\hline & 1568 & 12.38 & 0.637 & (CS)33.48 & - & - & [162] \\
\hline & 1556.86 & 2.47 & - & 6.77 & 0.065 & 0.01 & [163] \\
\hline & 1560 & 20.5 & 0.2 & 14.53 & 1 & 0.069 & [113] \\
\hline & 1569.5 & 4 & 0.71 & 12.09 & - & - & [164] \\
\hline & 1556.3 & 6.1 & 0.935 & 463 & 5.9 & - & [165] \\
\hline & (CS) 1530.4 & 2.1 & 1.21 & 8.968 & - & - & \\
\hline & (BS) & (period) 2 & 1.2 & 8.968 & - & - & [166] \\
\hline \multirow{5}{*}{$\begin{array}{l}\mathrm{MoSe}_{2} \\
\text { (TMD) }\end{array}$} & (CS)1557.3 & 5.4 & 0.798 & 15.38 & - & - & \\
\hline & (HML)1557.3 & 5.1 & 0.751 & $3.27 \mathrm{GHz}$ & $0.23 \sim 22.8$ & $14.6 \sim 6.7 \mathrm{pJ}$ & [167] \\
\hline & 1560 & 7.8 & 0.580 & 8.8 & - & 0.0913 & [168] \\
\hline & 1552 & 12.72 & 0.207 & 64.56 & - & - & [169] \\
\hline & 1558.35 & 2.9 & 1 & 16.27 & - & - & [170] \\
\hline \multirow{3}{*}{$\begin{array}{l}\mathrm{MoTe}_{2} \\
\text { (TMD) }\end{array}$} & 1561 & 24.9 & 0.1119 & 96.323 & 23.4 & - & [171] \\
\hline & 1532.5 & 1.5 & 2.57 & 6.95 & 1.7 & - & [172] \\
\hline & 1559.57 & 11.76 & 0.229 & 26.601 & 57 & 2.14 & [134] \\
\hline
\end{tabular}


Table 1. Cont.

\begin{tabular}{|c|c|c|c|c|c|c|c|}
\hline SA & $\begin{array}{c}\text { Center } \\
\text { Wavelength (nm) }\end{array}$ & $\begin{array}{c}3 \mathrm{~dB} \\
\text { Bandwidth (nm) }\end{array}$ & $\begin{array}{c}\text { Pulse } \\
\text { Duration (ps) }\end{array}$ & $\begin{array}{l}\text { Repetition } \\
\text { Rate (MHz) }\end{array}$ & $\begin{array}{c}\text { Output } \\
\text { Power (mW) }\end{array}$ & $\begin{array}{l}\text { Pulse Energy } \\
\text { (nJ) }\end{array}$ & Ref. \\
\hline \multirow{7}{*}{$\begin{array}{l}\mathrm{WS}_{2} \\
(\mathrm{TMD})\end{array}$} & 1565 & 8.23 & 0.332 & 31.11 & 0.43 & - & \multirow{2}{*}{ [173] } \\
\hline & 1566 & 5.6 & 0.457 & 21.07 & 0.32 & - & \\
\hline & 1540 & 114 & 0.067 & 135 & - & - & [133] \\
\hline & 1572 & 5.2 & 0.595 & 25.25 & - & - & [174] \\
\hline & (DS)1565.5 & 14.5 & 21.1 & 8.05 & 1.8 & 0.22 & [175] \\
\hline & 1558.5 & - & 0.675 & 19.58 & 0.625 & - & [176] \\
\hline & 1563.8 & 5.19 & 0.524 & 19.57 & 2.64 & 0.134 & [177] \\
\hline $\begin{array}{l}\mathrm{WSe}_{2} \\
\text { (TMD) }\end{array}$ & 1556.42 & 6.06 & 0.477 & 14.02 & - & - & [117] \\
\hline $\begin{array}{l}\mathrm{WTe}_{2} \\
(\mathrm{TMD})\end{array}$ & 1556.2 & 4.14 & 0.77 & 13.98 & - & - & [178] \\
\hline \multirow{5}{*}{ MXene } & 1550 & 42.54 & 0.104 & 20.03 & - & 0.065 & [179] \\
\hline & 1567.3 & 3.1 & 0.946 & 8.24 & - & - & [56] \\
\hline & 1557 & 5 & 0.66 & 15.4 & 0.05 & - & [33] \\
\hline & 1555.01 & 22.2 & 0.159 & 7.28 & 3 & 0.41 & [180] \\
\hline & 1565.4 & 3.4 & 5.3 & 8.25 & - & - & [181] \\
\hline BP QD & 1561.7 & 3 & 0.882 & 5.47 & - & - & [24] \\
\hline$(0 \tilde{D})$ & 1560.3 & 2.2 & 1.2 & 5.62 & 2.23 & 0.45 & [182] \\
\hline
\end{tabular}

The corresponding spectral bandwidth changed from $7.7 \mathrm{~nm}$ to $8.4 \mathrm{~nm}$ to $8.6 \mathrm{~nm}$, indicating that the SA possesses different pulsating abilities depending on the over-cladding index, which affects the pulse formation for a given laser cavity. Consequently, this may allow one to control the soliton pulse bandwidth and pulse width of the generated ultrafast laser through appropriate selection of the over-cladding material with various refractive indexes.

Although ultrafast fiber lasers based on graphene SA have been developed extensively, numerous deficiencies with graphene SA have progressively been revealed through growing investigation. Firstly, the absorption efficiency of $2.3 \%$ per layer results in reduced modulation depth which limits its advanced application in ultrafast fiber lasers. Even if a higher number of graphene layers elevate the modulation depth, the unsaturated loss, in this case, declines the performance of the fiber laser. Secondly, the tunable operating wavelength plays a critical role in the saturation threshold of graphene SA. A shorter operating wavelength exhibits a higher saturation threshold in graphene SA. This implies graphene as comparatively proper SA for fiber laser operating in the mid-infrared range but marginally worse performance while working in shorter wavelengths.

\subsection{Ultrafast Fiber Laser Based on CNT SA}

The first verification of CNTs as SA in an ultrafast fiber laser system took place in 2003 by Set et al., and ultrashort pulses of $\sim 1$ ps were demonstrated in $1550 \mathrm{~nm}$ [183]. Subsequently, CNT SAs have been rapidly adopted by many research groups. The most popular type of SWNT SA used in fiber lasers concentrates on polymer composite film, which is mechanically or optically sandwiched between fiber connectors. Another approach based on the evanescent field can be a candidate, and SWNTs can be coated on a Dshaped fiber [122], microfiber [184], or injected into micro slots [185,186], photonic crystal fiber [187], and hollow-core optical fiber (HOF) [188]. Choi et al. demonstrated the nonlinear interaction scheme of SWCNTs with laser light by using the HOF, which offers the advantages of robust, efficient, and long interaction of guided light with SWCNTs with a simple fabrication process (inset of Figure 7a) [188]. The HOF filled with low concentration SWCNT/polymer composite exhibiting broadband absorption is prepared as an in-line SA, resulting in a passively mode-locked fiber laser with the spectral bandwidth; the pulse duration and repetition rate of the laser output are $5.5 \mathrm{~nm}, 490 \mathrm{fs}$, and $18.5 \mathrm{MHz}$, 
respectively (Figure $7 \mathrm{~b}, \mathrm{c}$ ) [188]. In another demonstration, a dissipative soliton fiber laser with high pulse energy $(>30 \mathrm{~nJ})$ based on a single-walled carbon nanotube saturable absorber (SWCNT-SA) on SPF was reported by Jeong et al. [60].

(a)

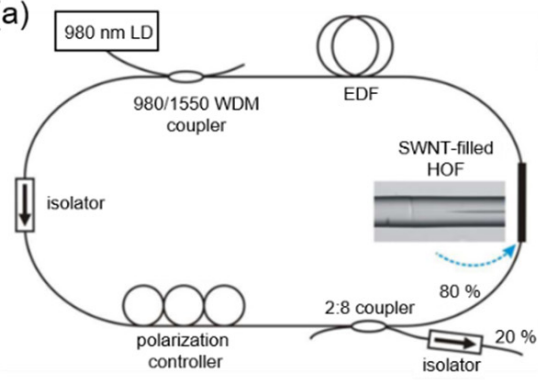

(d)

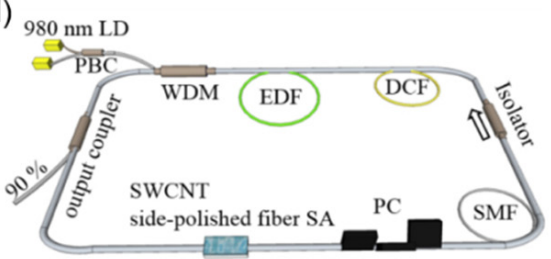

(b)

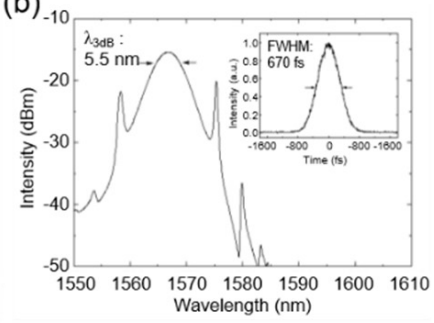

(e)

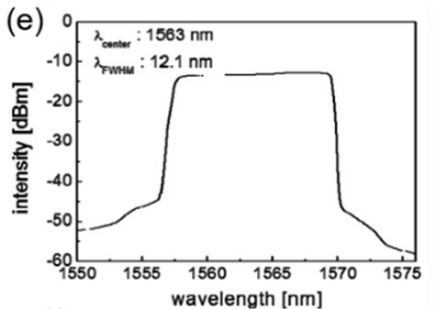

(c)
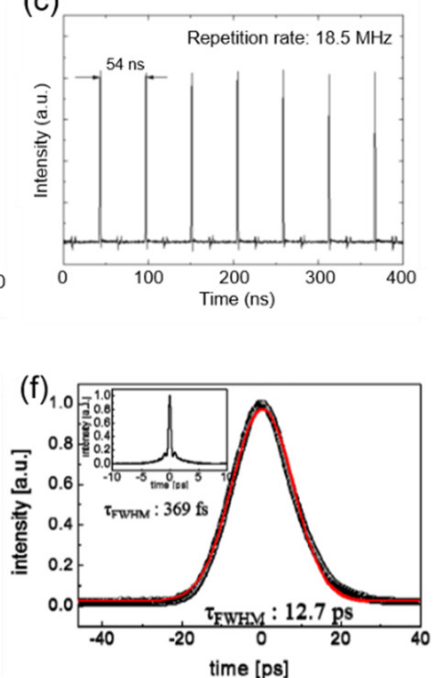

Figure 7. 1D SWCNT SA-based mode-locked fiber laser: $(\mathbf{a}-\mathbf{c})$ Conventional soliton: (a) Schematic of the fs fiber laser using the SWCNT-filled HOF. The inset figure shows the spliced image between the normal SMF and HOF, where adiabatic mode transition occurs. (b) Measured optical spectrum and pulse duration (inset) of the mode-locked fiber laser. (a-c) Reproduced with permission [188]. Copyright 2009, The Optical Society of America. (c) The output pulse train of the laser shows a repetition rate of $18.5 \mathrm{MHz}$. (d-f) Dissipative soliton: (d) Configuration of the fiber ring laser including the SWCNT-SA and the DCF. (e) The optical spectrum of the mode-locked laser at net cavity dispersion of $0.087 \mathrm{ps}^{2}$ and (f) Measured pulsed duration fitted with Gaussian pulse. The inset shows the pulse compressed by additional SMF at extra-cavity. (d-f) Reproduced with permission [60]. Copyright 2014, The Optical Society of America.

A laser cavity generates a dissipative soliton mode-locked pulsed laser only when the laser cavity net dispersion is in the normal dispersion regime. A dispersion compensating fiber (DCF) with large normal dispersion at $1550 \mathrm{~nm}$ was inserted along with SMF-28e (anomalous dispersion at $1550 \mathrm{~nm}$ ) in the cavity to realize the normal net cavity dispersion, as shown in Figure 7d. Stable passive mode-locking of a dissipative soliton laser was obtained at a net cavity dispersion of around $0.141 \mathrm{ps}^{2}$. The generated dissipative soliton exhibits spectral bandwidth of $12.1 \mathrm{~nm}$ with a flat top spectral shape at the central wavelength of $1563 \mathrm{~nm}$, as shown in Figure 7e. The flat-top behavior of the generated soliton pulse is evidence of dissipative soliton mode-locked pulsed laser. The laser stably delivers linearly chirped pulses with a pulse duration of $12.7 \mathrm{ps}$ (Figure $7 \mathrm{f}$ ), and the average power of the laser output is measured as $335 \mathrm{~mW}$ at an applied pump power of $1.27 \mathrm{~W}$. The corresponding pulse energy is estimated to be $34 \mathrm{~nJ}$ at the fundamental repetition rate of $9.80 \mathrm{MHz}$; this was the highest value reported in all-fiber Er-doped mode-locked laser using an SWCNT-SA.

\subsection{Ultrafast Fiber Laser Based on Other 2D SAs}

Following an extensive investigation with 2D graphene SA and 1D CNT SA for ultrafast fiber laser, other LD materials-based SAs have also attracted attention to build ultrafast mode-locked fiber laser. In 2014, black phosphorus started to achieve prevalent curiosity due to its unique electro-optical properties [84]. The interesting feature of BP is its band structure which can vary depending on the thickness or number of BP layers. The bandgap of BP reduces with increasing the number of layers or BP thickness because of interaction among the BP layers. The bandgap of bulk BP is $0.3 \mathrm{eV}$, which estimates that $\mathrm{BP}$ is a highly suitable contender for both mid-infrared and near-infrared SAs. One of the 
unique features of BP is its direct bandgap regardless of the changes in thickness. Compared to graphene, the relaxation time in BP has been found to be faster in the mid-infrared and near-infrared region revealed by Wang et al. using a pump-probe experiment, which suggested the higher ability for pulse narrowing compared to graphene [89]. Consequently, $\mathrm{BP}$, with its direct bandgap feature, provides valuable aspects towards the application of ultrafast nonlinear optics and optoelectronics. Numerous ML ultrafast fiber lasers based on BPs have been successfully investigated and recognized. Chen et al., for the first time, successfully constructed a BP-based SA and engaged it in a fiber laser ring cavity to generate stable ultrafast mode-locked fiber laser operating at $1571.45 \mathrm{~nm}$ with a pulse width of $946 \mathrm{fs}$ and $3 \mathrm{~dB}$ bandwidth of $2.9 \mathrm{~nm}$ [110]. The stability of the laser was confirmed by a signal-to-noise (SNR) ratio of $70 \mathrm{~dB}$. Along with the EDFL operating at $1.55 \mu \mathrm{m}$, BP-based SA has also been examined in the $1 \mu \mathrm{m}$ region achieved by YDFL. Hisyam et al. demonstrated MLFL using BP SA in a YDFL ring cavity, which generates $1 \mu \mathrm{m}$ modelocked soliton pulse with $7.54 \mathrm{ps}$ and the highest ever output power of $80 \mathrm{~mW}$ at their time of report [189]. The pulse energy was measured to be 5.93 nJ. Pawliszewska et al. obtained $2 \mu \mathrm{m}$ holmium-doped all-fiber lasers having a pulse duration of $1.3 \mathrm{ps}$, centered at $2094 \mathrm{~nm}$ with a bandwidth of $4.2 \mathrm{~nm}$ using BP SA [190]. Significant work on BP SA in the divergent wavelength range of 1-2 $\mu \mathrm{m}$ reveals the broadband absorption characteristics of BP. Jin et al. achieved the shortest pulse duration using BP-based SA at the time of their report [135]. A highly functional inkjet printing technology with high scalability was employed to fabricate the SA based on BP. The exfoliated BP flakes are shown in Figure 8a. Ultrafast fiber laser with this BP SA in an EDFL ring cavity exhibited the pulse width of $102 \mathrm{fs}, 3 \mathrm{~dB}$ bandwidth of $40 \mathrm{~nm}$ at $1555 \mathrm{~nm}$, and as shown in Figure 8a-c. Although the ultrafast fiber laser based on BP SA has been developed extensively with its wideband absorption characteristics and the ability to shorten the pulse width, numerous deficiencies with BP SA have progressively been revealed through growing investigation. Mainly, its instability to environmental factors such as humidity and temperature is detrimental to the fiber laser system. The physical properties of BP are highly sensitive to air. BP increases in its volume unexpectedly if it is exposed to air due to its large affinity for water.

Consequently, the BP surface decayed as time goes by if it was not efficiently passivated for a long time [192]. The optical properties of BP are certainly affected by its environmentally unstable behavior, thus influencing the execution of high-performance fiber lasers with BP SA. Moreover, the BP SA is prone to damage under high power laser due to its unavoidable thermal effects in the air, further limiting its application in elevated power regimes [114].

Inspired by the domination of 2D graphene as an SA for fiber lasers, few-layer 2D bismuthine also has been introduced by Lu et al. as an SA, owing to its direct bandgap at $1550 \mathrm{~nm}$. Bismuthine's optical bandgap is tunable and controlled by changing the number of layers. By increasing the layer number from one to six layers, it exhibits an optical bandgap varying from $1.028 \mathrm{eV}$ to $0.747 \mathrm{eV}$ [191]. They investigated few-layer bismuthine using various tools including atomic force microscopy (AFM), which confirmed the thickness of prepared few-layer bismuthine SA as $4 \mathrm{~nm}$ with a smooth surface as shown in Figure 8d. Generated ultrafast mode-locked fiber laser in the anomalous dispersion regime operating at $1559.18 \mathrm{~nm}$ has a spectral bandwidth of $4.64 \mathrm{~nm}$ and pulse duration of 652 fs (Figure 8e,f)

MXene, as a recently developed new 2D material, has attracted considerable attention because of its graphene-like but highly tunable and tailorable electronic/optical properties. Researchers found that a typical MXene has efficient SA with negligible lossy nonlinear absorption components in the spectral range $800-1800 \mathrm{~nm}$, which is indicated in a typical MXene, $\mathrm{Ti}_{3} \mathrm{C}_{2} \mathrm{~T}_{\mathrm{x}}$, which was deliberately chosen as the investigation object to highlight broadband nonlinear optical response in the near-infrared region [180]. In 2018, Jiang et al. investigated the broadband non-linear photonics of $\mathrm{Ti}_{3} \mathrm{C}_{2} \mathrm{~T}_{\mathrm{x}}$ by depositing $\mathrm{Ti}_{3} \mathrm{C}_{2} \mathrm{~T}_{\mathrm{x}}$ solution onto a side-polished fiber [180], where stable mode-locking was achieved in both Yb- and Er-doped fiber lasers operating at the wavelength of $\sim 1 \mu \mathrm{m}$ and $\sim 1.55 \mu \mathrm{m}$, respectively. 
Er-doped fiber laser results are depicted in Figure 8g-i. Highly stable self-started CWML is readily obtained when the pump power is above $60 \mathrm{~mW}$. The ultrashort pulse duration of $159 \mathrm{fs}$ was obtained with the spectral bandwidth of $22.2 \mathrm{~nm}$ operating at $1555.05 \mathrm{~nm}$. The output power, pulse energy, and peak power at the pump power of $238 \mathrm{~mW}$ are $3 \mathrm{~mW}$, $410 \mathrm{pJ}$, and $2578.6 \mathrm{~W}$, respectively.
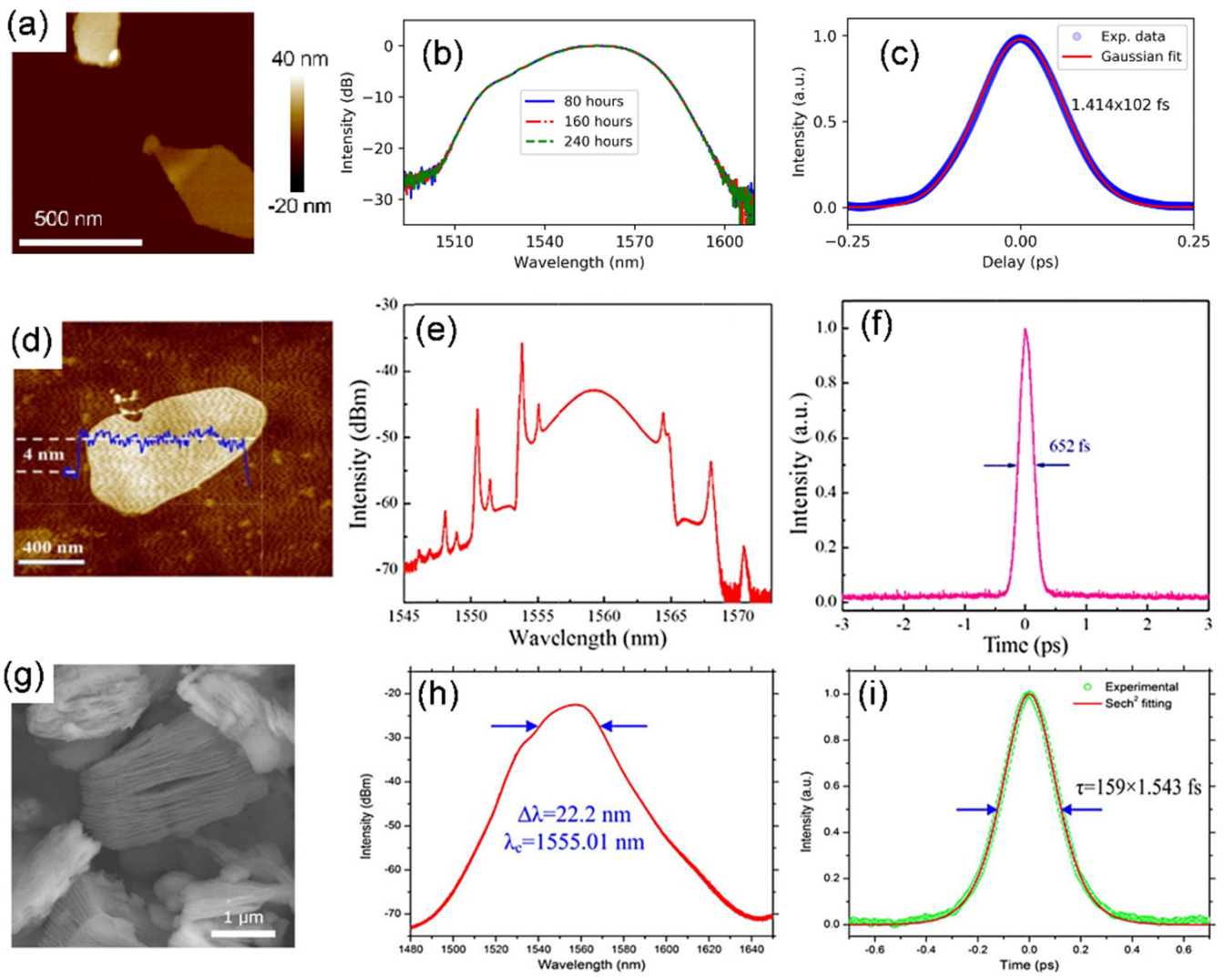

Figure 8. Mode-locked ultrafast fiber laser in the NIR region with various $2 \mathrm{D}$ SAs such as $\mathrm{BP}$ (a-c), Bismuthine (d-f), and $\mathrm{Ti}_{3} \mathrm{C}_{2} \mathrm{~T}_{\mathrm{x}} \mathrm{MXene}(\mathrm{g}-\mathbf{i})$. (a) AFM micrograph of selected exfoliated BP fakes; (b) Optical spectrum with a bandwidth of $40 \mathrm{~nm}$ acquired after $80 \mathrm{~h}$ (blue curve), $160 \mathrm{~h}$ (red dot line), and $240 \mathrm{~h}$ (green dot line), respectively; (c) Autocorrelation trace with a Gaussian fit. (a-c) Reproduced with permission. Copyright 2018, The Optical Society of America [135]. (d) AFM image of few-layer bismuthine. (e) mode-locked soliton pulse spectrum with $3 \mathrm{~dB}$ bandwidth of $4.64 \mathrm{~nm}$, and (f) autocorrelation trace of mode-locked ultrafast laser showing the pulse width of $652 \mathrm{fs}$. (d-f) Reproduced with permission. Copyright 2018, Wiley-VCH [191]. (g) SEM image of $\mathrm{Ti}_{3} \mathrm{C}_{2} \mathrm{~T}_{\mathrm{x}}$, (h) mode-locked soliton pulse spectrum with $3 \mathrm{~dB}$ bandwidth of $22.2 \mathrm{~nm}$, and (i) autocorrelation trace of mode-locked fiber laser showing the pulse width of 159 fs. (g-i) Reproduced with permission. Copyright 2017, Wiley-VCH [180].

\subsection{Ultrafast Fiber Laser Based on TMD and TI SAs}

TMDs, because of their various types with numerous members in the group, have inhabited the effective prominence as prospective contenders of SAs [162,175,178,193-197]. Among other candidates after graphene, which has been extensively researched in the nonlinear optics field, TMD is discovered to execute well in terms of ultrafast carrier dynamics, switchable bandgap, and higher-order nonlinear optical response. At present, some TMD materials such as $\mathrm{MoS}_{2}, \mathrm{MoTe}_{2}, \mathrm{MoSe}_{2}, \mathrm{WSe}_{2}$, and $\mathrm{WS}_{2}$ have produced crucial breakthroughs in ultrafast fiber lasers [162,175,178,193-197]. For example, the $\mathrm{MoS}_{2}$ bandgap transforms from indirect to direct while the thickness decreases from bulk to monolayer, along with the bandgap rising from 1.8 to $1.29 \mathrm{eV}$ [198]. Moreover, $\mathrm{MoS}_{2}$ exhibits a larger third-order nonlinear optical response compared to graphene. In addition to this, $\mathrm{MoS}_{2}$ 
highlights a carrier lifetime of nearly $100 \mathrm{ps}$ and ultrafast intraband relaxation time as short as $30 \mathrm{fs}$ [196]. Table 1 includes the properties of ultrafast fiber lasers with various TMD SAs. Among these TMDs, layered $\mathrm{MoS}_{2}$ was first studied. In 2014, the SA behavior of few-layer $\mathrm{MoS}_{2}$ was initially observed $[194,197,199]$. Both the conventional soliton and dissipative soliton mode-locked fiber laser have been reported by individual groups using anomalous dispersion and normal dispersion fiber laser ring cavity, respectively. Xia et al. demonstrated an Er-doped ultrafast fiber laser passively mode-locked by a multilayer $\mathrm{MoS}_{2} \mathrm{SA}$ prepared by a CVD method and transferred onto the end-face of a fiber connector to build a conventional soliton mode-locked fiber laser pulses operating at $1.57 \mathrm{um}$ wavelength in anomalous dispersion regime as shown in Figure 9a-c [200].
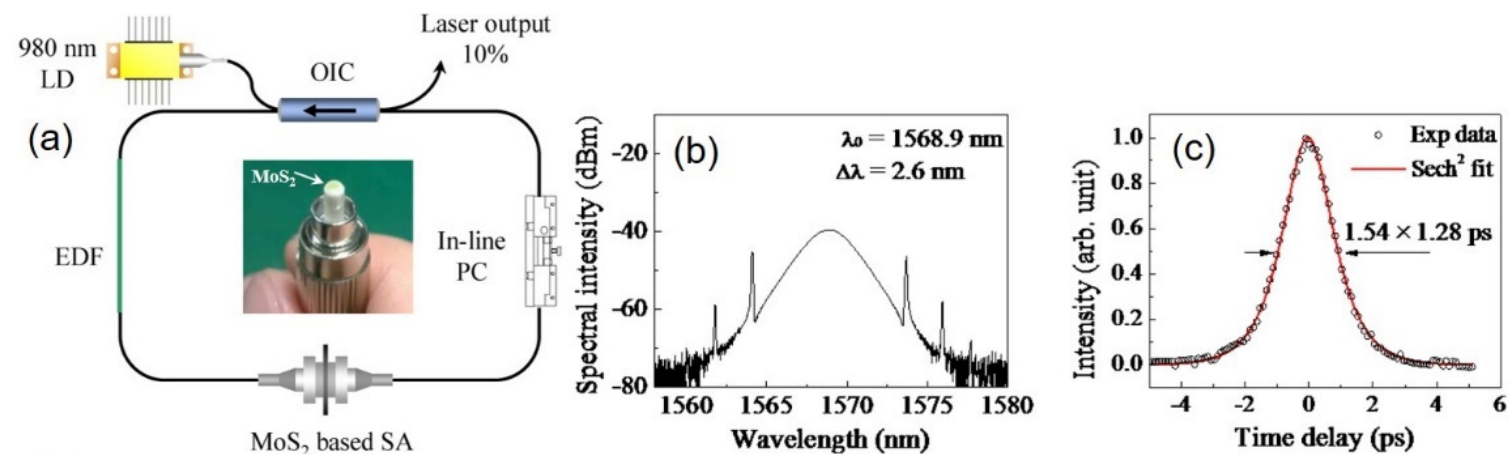

(d)
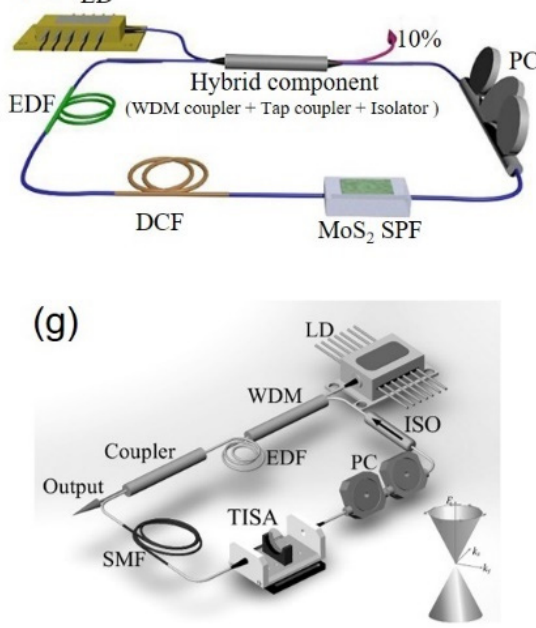

(e)
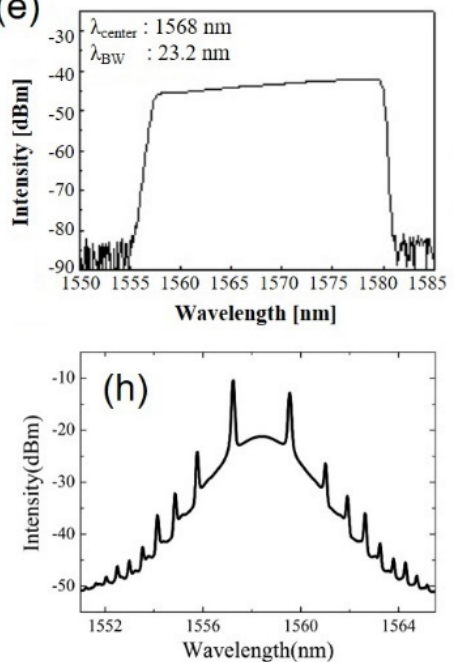
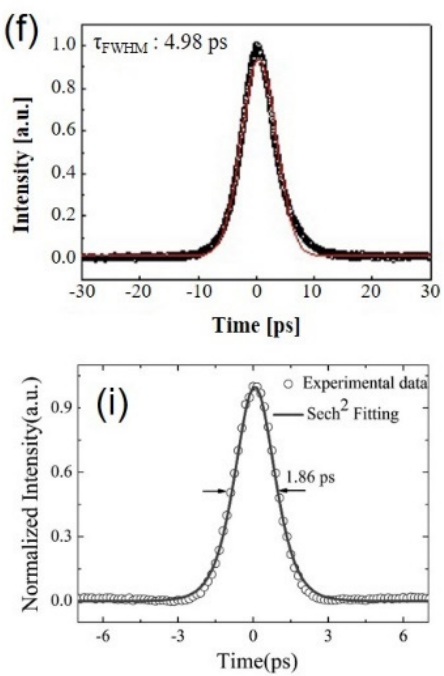

Figure 9. Mode-locked ultrafast fiber laser in the NIR region with various 2D SAs such as one of the TMDs named MoS 2 SA (a-f) and one of the TIs named $\mathrm{Bi}_{2} \mathrm{Te}_{3}(\mathbf{g}-\mathbf{i})$. (a-c) CS with $\mathrm{MoS}_{2} \mathrm{SA}$ : (a) A schematic diagram of the fiber ring laser in anomalous dispersion with $\mathrm{MoS}_{2}$ SA sandwiched in between two SMF (inset: Photograph of a fiber connector coated with multilayer $\mathrm{MoS}_{2}$ ); (b) Optical spectrum of conventional soliton mode-locked pulse with a bandwidth of $2.6 \mathrm{~nm}$; (c) Autocorrelation trace with a Sech ${ }^{2}$ fit showing pulse duration of $1.28 \mathrm{ps}$. (a-c) Reproduced with permission. Copyright 2014, The Optical Society [200]. (d-f) DS with $\mathrm{MoS}_{2}$ SA (d) A schematic diagram of the fiber ring laser in normal dispersion with $\mathrm{MoS}_{2}$ SA deposited on SPF. (e) The optical spectrum of the mode-locked laser at net cavity dispersion of $+0.095 \mathrm{ps}^{2}$ and (f) Measured pulsed duration fitted with Gaussian pulse. (d-f) Reproduced with permission. Copyright 2014, The Optical Society [162]. (g-i) CS with $\mathrm{Bi}_{2} \mathrm{Te}_{3} \mathrm{SA}$ : (g) mode-locked fiber laser cavity comprising $\mathrm{Bi}_{2} \mathrm{Te}_{3} \mathrm{SA}$, (h) mode-locked optical spectrum with $3 \mathrm{~dB}$ bandwidth of $2.69 \mathrm{~nm}$, and (i) autocorrelation trace of mode-locked soliton pulse with the FWHM width of 1.86 ps. (g-i) Reproduced with permission. Copyright 2012, AIP [201].

Resultant output soliton pulses showed central wavelength, spectral width, pulse duration, and repetition rate of $1568.9 \mathrm{~nm}, 2.6 \mathrm{~nm}, 1.28 \mathrm{ps}$, and $8.288 \mathrm{MHz}$, respectively. Khazaeizhad et al., in another work, successfully employed a CVD-grown multilayer $\mathrm{MoS}_{2}$ SA in a passively mode-locked Er-doped fiber laser to achieve both soliton and dissipative 
soliton pulses [162]. Their dissipative soliton pulses characteristics operating at the near infrared region are shown in Figure $9 \mathrm{~d}-\mathrm{f}$. The normal dispersion cavity was achieved by optimizing the net dispersion of the cavity by adding a segment of dispersion compensating fiber (DCF) in the cavity, as seen in Figure 9d. The stable dissipative soliton pulses with 4.98 ps pulse width at the repetition rate of $26.02 \mathrm{MHz}$ showing a broad spectral width of $23.2 \mathrm{~nm}$. In anomalous dispersion regime, they also obtained soliton pulses with pulse duration of $637 \mathrm{fs}$ at the repetition rate of $33.48 \mathrm{MHz}$, and with a spectral width of $12.38 \mathrm{~nm}$ in an anomalous dispersion cavity. These findings have greatly promoted the development of few-layer $\mathrm{MoS}_{2}$ in mode-locked lasers, leading to significant progress in this area.

As new LD graphene-like materials, TIs have been discovered with an energy band structure of symmetry Dirac cone due to their strong spin-orbit interaction, which implies that they can be developed into a new kind of SAs [202,203]. TIs have a nonzero bandgap and a large modulation depth (up to $95 \%$ ), which are beneficial for improving the performance of mode-locked fiber lasers. Various mode-locked fiber lasers based on TIs, including $\mathrm{Bi}_{2} \mathrm{Se}_{3}[204,205], \mathrm{Bi}_{2} \mathrm{Te}_{3}[107,108]$, and $\mathrm{Sb}_{2} \mathrm{Te}_{3}$ [53], have been developed, most of them are summarized in Table 1 with their mode-locked ultrafast EDFL. TIs were also confirmed as possessing excellent nonlinear optical properties and were used as SAs for demonstrating the ultrafast fiber laser in 2012 [201], as shown in Figure 9g-i. Zhao et al. reported in a first example among all $\mathrm{TI}$ that $\mathrm{Bi}_{2} \mathrm{Te}_{3} \mathrm{SA}$ exhibited very-high-modulation-depth (up to $95 \%$ ) saturable absorber and used as a passive mode locker for ultrafast pulse formation at the telecommunication band as shown in Figure $9 \mathrm{~g}-\mathrm{i}$. In an erbium-doped fiber laser with the help of this SA, self-started mode-locked pulses centered at $1558.4 \mathrm{~nm}$ with a pulse width of 1.21 ps could be directly generated out of the laser cavity. These results indicate that, in addition to their established attractive electrical and thermal properties, TIs also have attractive application prospects for an ultrafast fiber laser.

All these LD SA devices also have been studied to build Q-switched or Q-switched mode-locked fiber laser by changing the cavity conditions such as polarization state, pump power or even by changing the fiber length of the cavity $[67,68]$. That means there is an additional regime of the fiber laser using these LD SA, including Q-switching and boundstate soliton mode-locking, to achieve high repetition rate fiber lasers in the gigahertz ranges useful for diverse applications. Therefore, the controllability of the fiber laser operating at different regimes using these LD SA would be of great interest due to its compatibility with various fiber-optic systems.

\section{Externally Controlled Ultrafast Fiber Laser}

To date, there are very few investigations reported on the active control of fiber laser using the LD SA, such as graphene and CNT [25-27,66-68]. These can be done both optically and/or electrically. It is noted that most of these active controls were done for evanescent field interaction cases, as it provides the facilitated device fabrication on the SPF surface along with the high functionality owing to the effective polarization sensitivity of evanescent field wave incident on SPF surfaces. It has been demonstrated that the fermi level of LD SA can be shifted by applying external gate bias to the LD-based capacitor structure, which plays a crucial role in tuning the modulation depth of the SA hence effectively control the fiber laser operating regime $[25,67]$. Apart from the evanescent field interaction cases, few attempts to simplify the design of actively mode-locked lasers have been made by employing a compact LD SA-based electro-optic modulator which controls the linear optical absorption as well as the modulation depth of the device upon applied external electrical signal [26,27]. These electro-optic modulators have been utilized in fiber laser for active control of pulse generation with tunable repetition rate along with mode-locking and harmonic mode-locking (HML) operation. As for the external optical bias, the nonlinear absorption in the SA can be substantially controlled via cross-absorption modulation (XAM) using evanescent field interaction; thus, the fiber laser operation was optically controlled [68]. A few of the recent works on externally controlled 2D SA for tunable fiber lasers and their characteristics are summarized in Table 2. The following 
section will briefly review those works covered by both electrically and optically controlled switchable fiber lasers.

Table 2. Performance summary of Externally controlled LD SA for tunable fiber laser.

\begin{tabular}{|c|c|c|c|c|c|c|c|}
\hline LD SA (Type of Control) & $\begin{array}{l}\text { Operating Voltage } \\
\text { (V) or } \\
\text { Control Beam } \\
\text { Power }(\mathrm{mW})\end{array}$ & $\begin{array}{l}\text { Fiber Laser } \\
\text { Regime } \\
\text { (QS or } M L)\end{array}$ & $\begin{array}{c}\text { Repetition Rate } \\
\text { (MHz) }\end{array}$ & $\begin{array}{c}\text { Pulse } \\
\text { Duration (ps) }\end{array}$ & $\begin{array}{l}3 \mathrm{~dB} \\
\text { Bandwidth } \\
(\mathrm{nm})\end{array}$ & $\begin{array}{c}\text { Center } \\
\text { Wavelength } \\
(\mathrm{nm})\end{array}$ & Ref. \\
\hline $\begin{array}{l}\text { Bi-layer graphene (Electrically } \\
\text { controlled-ion-liquid gated) }\end{array}$ & $\begin{array}{l}-1.05 \mathrm{~V} \\
-0.18 \mathrm{~V}\end{array}$ & $\begin{array}{l}\text { ML } \\
\text { QS }\end{array}$ & $\begin{array}{c}30.9 \\
25.4 \mathrm{kHz}\end{array}$ & $\begin{array}{c}0.423 \\
3.5 \mu \mathrm{s}\end{array}$ & $\begin{array}{l}8 \\
-\end{array}$ & $\begin{array}{l}1609 \\
1590\end{array}$ & [25] \\
\hline $\begin{array}{l}\text { Bi-layer Graphene(Electrically } \\
\text { controlled-PMMA) }\end{array}$ & $\begin{array}{c} \pm 4 \mathrm{~V} \\
-\end{array}$ & $\begin{array}{c}\text { ML } \\
\text { QS-Not tested }\end{array}$ & $\begin{array}{c}2.44 \\
-\end{array}$ & $\begin{array}{c}0.390 \\
-\end{array}$ & $\begin{array}{c}8.9 \\
-\end{array}$ & $\begin{array}{c}1547.5 \\
-\end{array}$ & [66] \\
\hline $\begin{array}{l}\text { Mono-layer Graphene } \\
\text { (Electro-optic modulator) }\end{array}$ & $\begin{array}{l}8 \mathrm{~V}(-4 \text { to }+4 \mathrm{~V} \\
4.35 \mathrm{MHz}) \\
8 \mathrm{~V}(-4 \text { to }+4 \mathrm{~V} \\
8.70 \mathrm{MHz})\end{array}$ & $\begin{array}{l}\text { ML } \\
\text { HML }\end{array}$ & $\begin{array}{l}4.35 \\
8.70\end{array}$ & $\begin{array}{l}1.44 \\
1.57\end{array}$ & $\begin{array}{r}1.8 \\
1.82\end{array}$ & $\begin{array}{l}1559.2 \\
1559.3\end{array}$ & [26] \\
\hline $\begin{array}{l}\text { Bi-layer Graphene (Electro-optic } \\
\text { modulator) }\end{array}$ & $\begin{array}{c}3.5 \mathrm{~V} \\
\text { (35 to } 65 \mathrm{KHz})\end{array}$ & QS & 35 to $65 \mathrm{KHz}$ & 1.93 to $5.54 \mu \mathrm{s}$ & 0.05 & $\begin{array}{c}1524.6 \text { to } \\
1561.7\end{array}$ & [27] \\
\hline $\begin{array}{l}\text { SWCNT (Electrically } \\
\text { controlled-ion-liquid gated) }\end{array}$ & $\begin{array}{l}0 \sim 0.7 \mathrm{~V} \\
0.8 \sim 1.9 \mathrm{~V}\end{array}$ & $\begin{array}{l}\text { ML } \\
\text { QS }\end{array}$ & $\begin{array}{c}50 \\
23.6 \sim 28.8 \mathrm{kHz}\end{array}$ & $\begin{array}{c}0.6 \\
-\end{array}$ & $\begin{array}{c}7.6 \\
-\end{array}$ & $\begin{array}{l}1558 \\
1559\end{array}$ & [67] \\
\hline $\begin{array}{c}\text { Monolayer graphene } \\
\text { (Optically controlled- } \\
\text { ion-liquid gated), } \\
\text { Biased by } 980 \text { nm CW pump beam }\end{array}$ & $\begin{array}{c}42 \mathrm{~mW} \\
(980 \mathrm{~nm}) \\
34 \mathrm{~mW} \\
(980 \mathrm{~nm}) \\
0 \mathrm{~mW} \\
(980 \mathrm{~nm}) \\
30 \mathrm{~mW} \text { Modulated } \\
\text { signals } \\
\text { Square pulse } \\
\text { (1 ms) }\end{array}$ & QS-ML & $\begin{array}{c}5.09 \\
20 \mathrm{kHz} \\
5.09 \mathrm{MHz} \\
8 \mathrm{kHz} \\
6.2 \sim 11.8 \mathrm{kHz} \\
1 \mathrm{~Hz}\end{array}$ & $20 \mu \mathrm{s}$ & - & $\begin{array}{l}- \\
- \\
-\end{array}$ & [68] \\
\hline
\end{tabular}

\subsection{Electrically Controlled Gate-Tunable Fiber Lasers}

Lee et al., for the first time, demonstrated electrically controllable all-fiber graphene SA operating in Q-switching and mode-locking regime depending on the external gatebias [25]. CVD grown, high-quality large-area graphene capacitor structure was fabricated on the SPF surface using a droplet of ion liquid on it as shown in Figure 10a. When the gate voltage is applied, the ions form an electric double layer (EDL) at the liquid/graphene interface with effective capacitance thickness around $1 \mathrm{~nm}$ over the entire graphene area. The exceptionally elevated capacitance of the electric double layer directs to an effective change in the Fermi level of graphene, which noticeably tunes the optical transmission of the incident light on the graphene SA at comparably lower operation voltage. As shown in Figure $10 \mathrm{~b}$, at zero gate bias voltage $\left(\mathrm{V}_{\mathrm{G}}\right)$, the TE mode undergoes large absorption of $3.47 \mathrm{~dB}(>50 \%)$ (solid orange line at $\mathrm{V}_{\mathrm{G}}=0 \mathrm{~V}$ ), while TM mode transmission rises by $0.09 \mathrm{~dB}$ (solid blue line at $\mathrm{V}_{\mathrm{G}}=0 \mathrm{~V}$ ). This result is due to the reduced scattering loss caused by incorporating ion-liquid over-cladding on top of graphene and the polished surface.

More importantly, the applied gate voltage actively tuned the optical transmission of the device. TE mode exhibited a comparably larger change in transmission from 39.2 to $83.4 \%$ compared to the TM mode (from 87.1 to $90.8 \%$ ) for $\mathrm{V}_{\mathrm{G}}$ varying from $0.7 \mathrm{~V}$ to $-1.8 \mathrm{~V}$. This optical measurement implies that $44.2 \%$ of total incident light TE mode recovered after interacting with the single-layer graphene. These changes in optical transmission occur because of the Fermi level shift in graphene by an external gate voltage. Upon applying gate bias, the Fermi level near the Dirac point experiences substantial change due to incomplete density of state of electrons enclosed in a 2D graphene, revealing large electro-optic absorption. The corresponding change of electron carrier density in graphene was analyzed by determining the electrical transport properties of the device, as shown in Figure 10c. While the Fermi energy level reaches half the incident photon energy $(\hbar \omega / 2)$, the maximum transition in optical transmission appears to happen. The Fermi level change of $0.40 \mathrm{eV}$, which is the half-photon energy of the incident light source used in their experiment $(1550 \mathrm{~nm})$, is directly connected to the gate voltage deviation of $1.65 \mathrm{~V}$, as described in Figure 10c. These integrated optical and electrical measurements and investigation could be a new technique to evaluate critical parameters like quantum capacitance and gate coupling 
efficiency without using complicated and expensive measurement systems. Nonlinear absorption characteristics of graphene such as saturation fluence and nonlinear modulation depth can be continuously tuned with the gate voltage, which can overcome the discrete nature of nonlinear absorption in stacked graphene sheets and be employed as functionally switchable devices. They also measured and observed the tunable nonlinear optical transmission as well as the varied modulation depth depending on the applied gate bias.
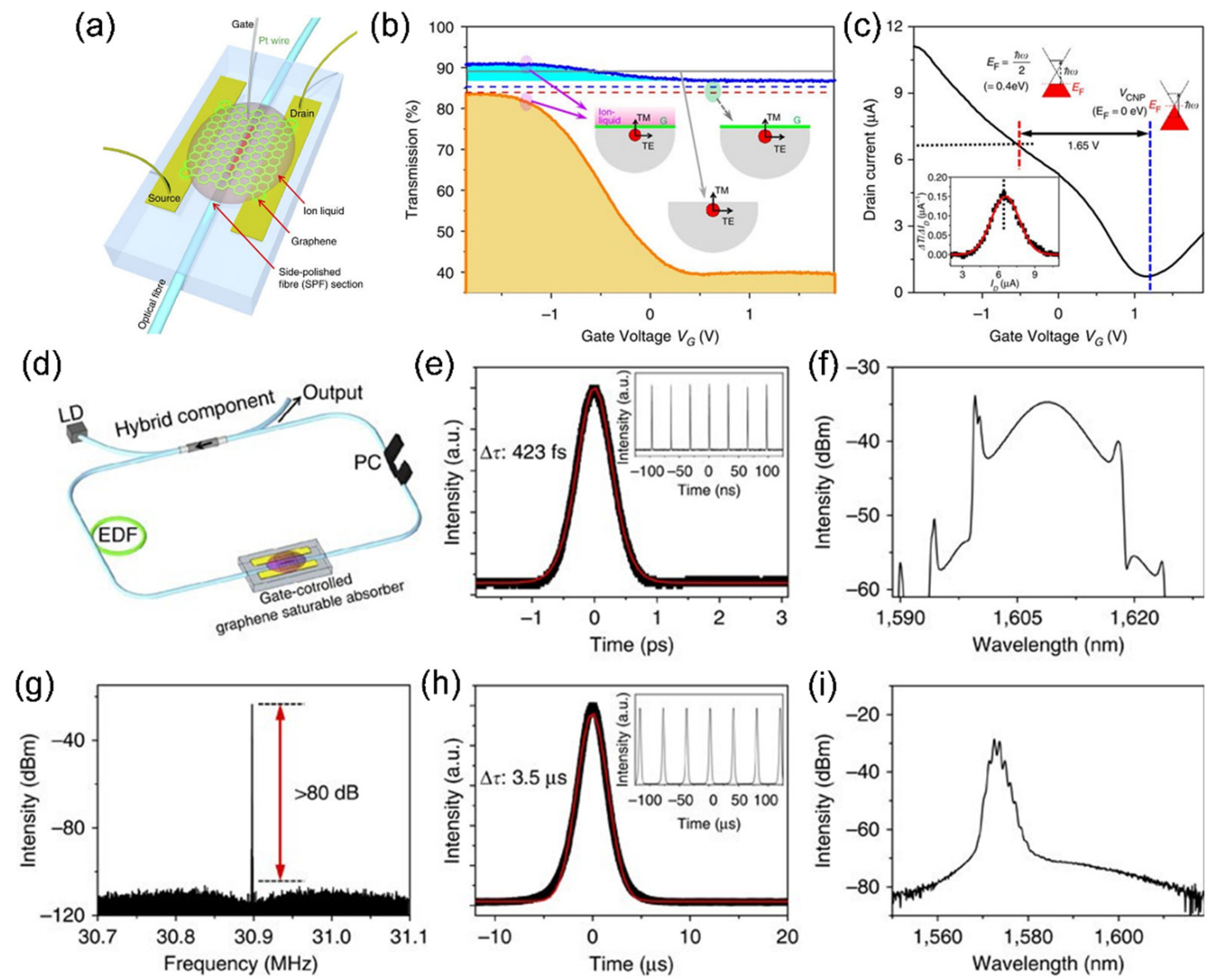

Figure 10. Electrically controlled fiber laser using an all-fiber graphene device and gate-variable properties of fiber laser operation. (a) Schematic diagram of gate-variable all-fiber graphene device. (b) Gate-controlled Optical transition properties of the device. (c) Gate-controlled Electrical transport properties of the device. (d) Fiber laser configuration, including fabricated all-fiber device with bilayer graphene. LD: laser diode; EDF: erbium-doped fiber; PC: polarization controller; hybrid component: an integrated wavelength-division multiplexer and isolator. (e-g) Characteristics of a passively modelocked fiber laser at an applied $\mathrm{V}_{\mathrm{G}}$ of $-1.05 \mathrm{~V}$; (e) Measured pulse duration of $423 \mathrm{fs}$ at a repetition rate of $30.9 \mathrm{MHz}$ (inset). (f) Laser output spectrum with a spectral bandwidth of $8 \mathrm{~nm}$ at $3 \mathrm{~dB}$. (g) The measured radio frequency spectrum of the laser output (h,i) Q-switched characteristics of a fiber laser at an applied $\mathrm{V}_{\mathrm{G}}$ of $-0.18 \mathrm{~V}$; (h) Measured output pulse duration of $3.5 \mathrm{~ms}$ at a repetition rate of $25.4 \mathrm{kHz}$ (inset) and (i) its optical spectrum. Reproduced with permission. Copyright 2015, Springer Nature [25].

The fiber laser was built up using this device with a bilayer graphene SA case, which shows a self-starting of passive mode-locking operation at the applied $\mathrm{V}_{\mathrm{G}}$ of $-1.05 \mathrm{~V}$ where the measured pulse duration was $423 \mathrm{fs}$ at a repetition rate of $30.9 \mathrm{MHz}$, as shown in Figure $10 \mathrm{~d}-\mathrm{f}$. The spectral bandwidth of the laser output was measured to be $8.0 \mathrm{~nm}$ at the central wavelength of $1609 \mathrm{~nm}$. The background noise level was $>80 \mathrm{~dB}$ from the signal of the fundamental repetition rate of the laser output as shown in Figure $10 \mathrm{~g}$, which indicates stable mode-locking operation on increasing $\mathrm{V}_{\mathrm{G}}$, the linear optical transmission decreases, while both modulation depth and saturation fluence of the SA increase. This significantly modifies the Q-switching instability condition, changing the fiber laser operation to Q- 
switching. Figure 10h,i shows measured Q-switched pulse duration $(3.5 \mu \mathrm{s})$ and optical spectrum, respectively, at the applied $\mathrm{V}_{\mathrm{G}}$ of $-0.18 \mathrm{~V}$. The repetition rate of the laser was measured as $25.4 \mathrm{kHz}$ (inset of Figure 10h). For an applied voltage larger than $0.14 \mathrm{~V}$ or less than $-1.65 \mathrm{~V}$, the fiber laser turns to continuous-wave operation.

Bogusławski et al. demonstrated an active mode-locked laser that achieved controlled ultrafast mode-locked laser pulses with tunable repetition rate by using a graphene-based electro-optic modulator (GEOM) as seen in Figure 11 [26]. The active mode-locking and active harmonic mode-locking of the erbium-doped fiber laser with output pulse duration of $1.44 \mathrm{ps}$ and pulse energy of $844 \mathrm{pJ}$ were achieved by the combination of the active modelocking technique and the intracavity nonlinear pulse compression effect. The GEOM was integrated with an EDF laser working at $1.56 \mu \mathrm{m}$ wavelength for active mode-locking. The experimental setup of the laser is presented in Figure 11a. The GEOM was inserted in a linear part of the cavity coupled with the ring-shaped part by a fiber circulator. A fiber collimator (L1) and an aspheric focusing lens ( $\mathrm{f}=\approx 4.6 \mathrm{~mm}$, L2) were used to extract the beam outside the fiber and focus on the surface of the GEOM. The active mode-locking operation occurred immediately when the modulating signal frequency was set to precisely match the roundtrip frequency of the laser cavity $\left(f_{0}=4.3505725 \mathrm{MHz}\right)$ and the pump power exceeds the $\mathrm{CW}$ lasing threshold of $18 \mathrm{~mW}$. The modulating electrical signal with the amplitude and frequency of $8 \mathrm{~V}$ (from -4 to $4 \mathrm{~V}$ ) and $4.35 \mathrm{MHz}$ respectively, was applied to GEOM as drive voltage to see the fundamental mode-locking operation with the repetition rate of $4.35 \mathrm{MHz}$ as shown in the pulse train (Figure 11b). As soon as the modulation signal frequency was raised to $8.7012 \mathrm{MHz}$, which corresponds to second harmonic of the laser cavity, the second harmonic mode-locking (HML) operation occurred at $1559 \mathrm{~nm}$ with the pulse repetition rate of $8.7 \mathrm{MHz}$ as shown in Figure 11c.
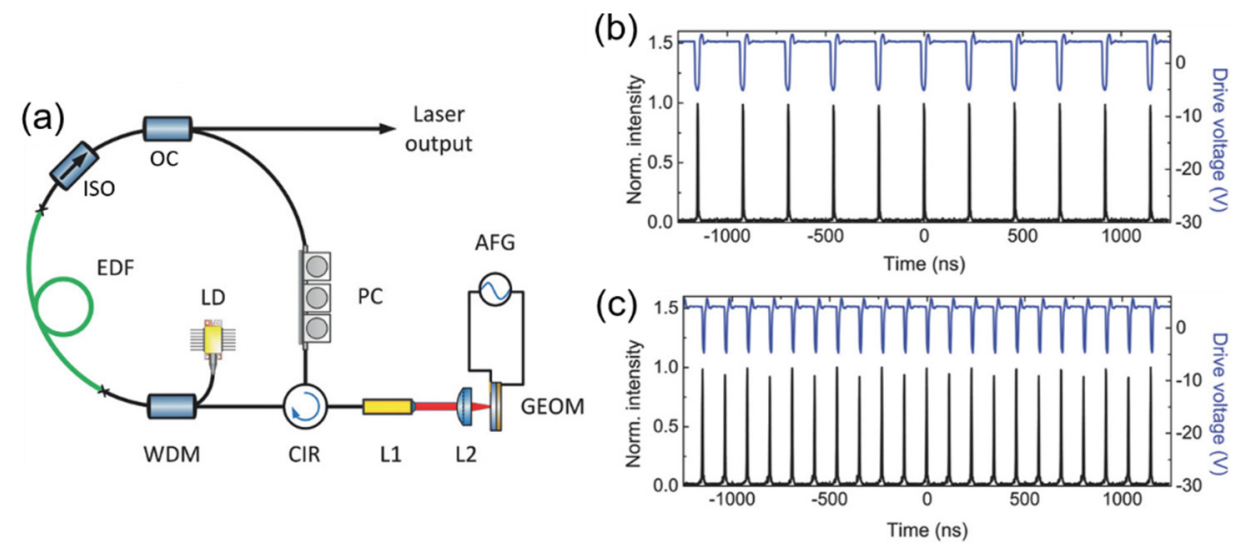

Figure 11. Graphene electro-optic modulator (GEOM) controlled mode-locked ultrafast fiber laser. (a) Laser cavity setup. EDF: erbium doped fiber; LD: laser diode; WDM: wavelength-division multiplexer; ISO: isolator; OC: output coupler; PC: polarization controller; CIR: circulator; L1: collimating lens; L2: focusing lens; AFG: arbitrary function generator. (b) Drive signal at the modulation frequency of $4.35 \mathrm{MHz}$ and synchronized output optical pulse train for fundamental mode-locking operation at the repetition rate of $4.35 \mathrm{MHz}$. (c) Drive signal at modulation frequency of $8.7 \mathrm{MHz}$ and synchronized output optical pulse train for second harmonic mode-locking operation at the repetition rate of 8.7 MHz. Reproduced with permission. Copyright 2018, Wiley-VCH [26].

Gladish et al., in another work, reported that electrochemical doping could tailor the nonlinear optical absorption of SWCNT films and demonstrated its application to control pulsed fiber laser generation in a similar manner [67]. The SWCNTs were manufactured by the aerosol CVD technique and followed by a dry transfer technique to a polarizationmaintaining side-polished fiber (PM-SPF) to execution of the fiber laser system. They exhibited a comprehensive mode-locked ultrafast pulsed laser employing this device capable of operating in both mode-locked and Q-switched regimes manipulated by the external gate voltage. Self-starting of mode-locking happened as the pump power was 
boosted up to $40 \mathrm{~mW}$. Stable mode-locked lasing at the fundamental pulse repetition rate of $50 \mathrm{MHz}$ and the spectrum width at half-maximum is $7.6 \mathrm{~nm}$ with $0.6 \mathrm{ps}$ pulse duration was obtained at zero gate voltage as shown in Figure 12a,b. If the applied gate voltage reached over the threshold voltage of $0.7 \mathrm{~V}$, the ML pulse disappeared, and the cavity operation regime was switched to the Q-switched laser. Microsecond pulses generated in the QS regime exhibited repetition rates in $\mathrm{kHz}$ regime (Figure 12c). If the gate voltage was further increased up to $1.9 \mathrm{~V}$, the Q-switched laser was persistent with an increasing repetition rate. The repetition rate of the Q-switched laser pulse was tuned from 23.6 to $28.8 \mathrm{kHz}$ by increasing the applied gate voltage from $0.8 \mathrm{~V}$ to $1.9 \mathrm{~V}$ (Figure 12d). The pulse energy of the laser was recorded as high as $12.5 \mathrm{~nJ}$.

(a)

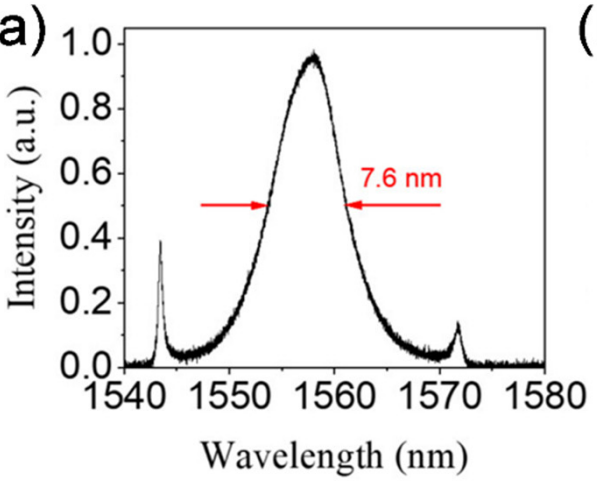

(c)

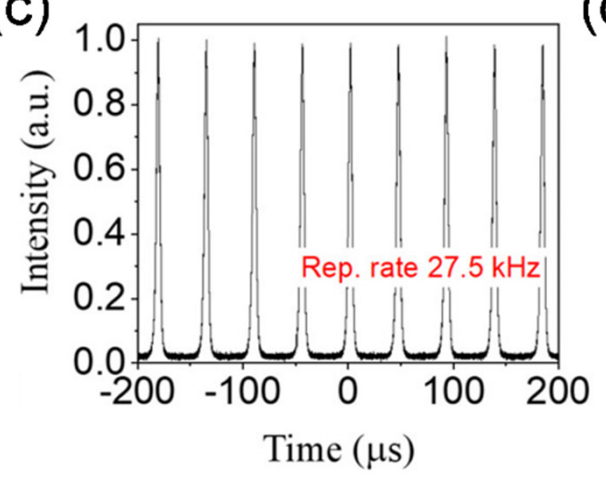

(b)

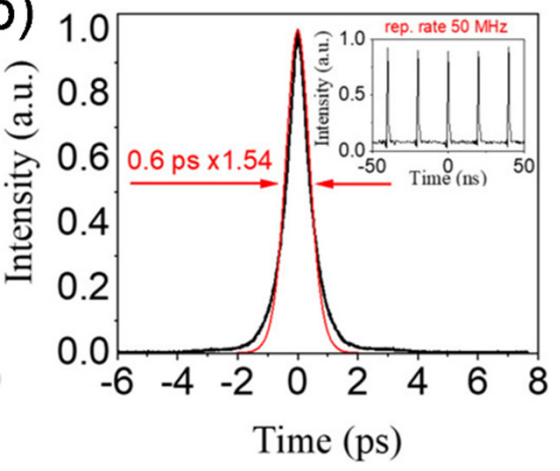

(d)

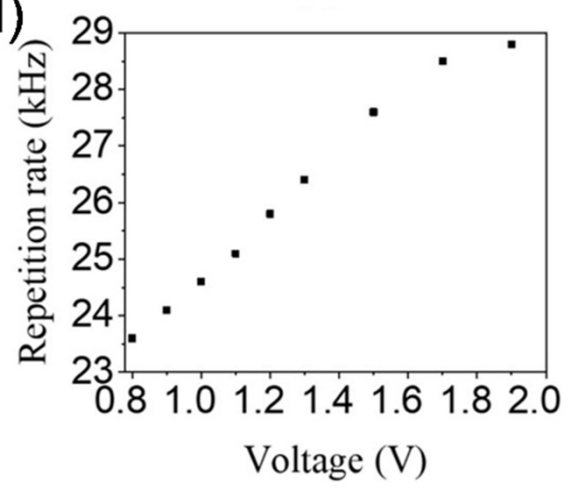

Figure 12. Electrically controlled fiber laser using SWCNT SA device and gate-variable properties of fiber laser operation. Soliton ML fiber laser characteristics at $\mathrm{V}_{\mathrm{G}}=0 \mathrm{~V}$ : (a) optical soliton pulse spectrum shows the $3 \mathrm{~dB}$ bandwidth of $7.6 \mathrm{~nm},(\mathbf{b})$ autocorrelation trace shows the pulse duration of $600 \mathrm{fs}$ with oscillation trace (inset showing repetition rate of $50 \mathrm{MHz}$ ) of the mode-locked pulse. QS fiber laser characteristics at $\mathrm{V}_{\mathrm{G}}>0.7 \mathrm{~V}$ : (c) oscillation trace of QS pulse with repetition rate of $27.5 \mathrm{kHz}$, (d) variation of QS pulse frequency as a function of applied gate voltage showing that, repetition rate is controlled in the range from $23.6 \mathrm{kHz}$ to $28.8 \mathrm{kHz}$ with applied gate voltage $\mathrm{V}_{\mathrm{G}}$ varying from $0.8 \mathrm{~V}$ to 1.9 V. Reproduced with permission. Copyright 2019, American Chemical Society [67].

\subsection{Optically Controlled Cross-Absorption Modulated Tunable Fiber Laser}

Apart from the electrical control, optically excited carriers also alternatively tune the linear optical absorption in graphene through Pauli blocking theory, which facilitated graphene-based devices for all-optical modulation in broadband scale [206]. This can adjust the optical properties of graphene SA on a nonlinear scale, such as modulation depth and non-saturable loss. This method was utilized in the fiber laser cavity by Sheng et al. to optically manipulate and tune the pulse width of a passively mode-locked ultrafast fiber laser based on graphene SA [207]. Cross absorption modulation (XAM) employing evanescent field interaction significantly modified the nonlinear SA in graphene. Gene et al., in the recent past, successfully accomplished different pulsed fiber laser regimes by optically controlling and manipulating the SA [68]. They displayed optically tuned 
in-line graphene SA with higher tunability in modulation depth by means of boosting the interaction of graphene SA with the incident evanescent field. The all-fiber graphene SA was manufactured by transferring a uniform and large-area single-layer graphene onto the side-polished fiber (SPF), as seen in Figure 13a. Nonlinear absorption properties of graphene SA were optically controlled by means of XAM in a graphene sheet. A shorter wavelength $(980 \mathrm{~nm})$ light was utilized to manipulate the absorption of the signal beam at a higher wavelength $(1550 \mathrm{~nm})$. As the graphene SA layer absorbed the control beam, the signal beam experienced less absorption by XAM [207]. In the case of the parallel polarization direction of TE mode along with the graphene layer at a low power level, the incident signal beam encounters only a slight transmission of $2.5 \%$ in the monolayer graphene as shown in Figure 13b. At a high-power level, 50.2\% of the transmission recorded in the absence of the applied control beam reveals the modulation depth of $47.7 \%$ over the $800 \mathrm{~mW}$ of signal power. The modulation depth reduced to $28.5 \%$ as soon as the incident control beam power reached $84 \mathrm{~mW}$. The graphene SA device was incorporated into an Er-doped fiber ring-laser system, as illustrated in Figure 13c. The laser cavity comprises two wavelength division multiplexing (WDM) couplers and two 980-nm laser diodes (LDs), pumping the EDF and the other to control the graphene SA. A pulsed fiber laser is capable of operating in several modes such as Q-switching, Q-switched mode-locking (QML), and CW mode-locking mode, which can be governed by manipulating the system parameters such as modulation depth, gain relaxation time, gain saturation power, smallsignal gain, and saturation power of the SA. Figure 13d shows the switching performance of the fiber laser regime as a function of SA modulation depth. Figure 13e-g illustrates experimental findings of the switching actions altered between different laser operating regimes achieved through active control graphene SA by manipulating the external control beam in a pulsed fiber laser setup. In the absence of a control beam $\left(P_{c}=0 \mathrm{~mW}\right)$, graphene SA in the ring cavity reveals the Q-switched laser (Figure 13e), with the pulse duration and repetition rate of $20 \mu \mathrm{s}$ and $8.0 \mathrm{kHz}$, respectively. The laser state was switched to QML if the control beam power was elevated to $34 \mathrm{~mW}$. A fine mode-locked pulse train at a repetition rate of $5.09 \mathrm{MHz}$ (inset of Figure 13f) is clearly observed within the $20 \mathrm{kHz}$ Q-switched pulses, as shown in Figure 13f. CW mode-locking status was achieved as the control beam power was increased to $42 \mathrm{~mW}$ (Figure 13g). In addition to these, they also examined the laser characteristics when a control beam with sinusoidal modulation frequency was applied to the graphene SA at a particular power of the control beam. It was seen that the generated Q-switched laser emitted from the cavity exhibited the repetition rate same as the modulation speed of the applied control beam. A Q-switched laser with a continuously tunable repetition rate in the range from $6.2 \mathrm{kHz}$ to $11.8 \mathrm{kHz}$ was obtained by manipulating the modulation frequency of the control beam. The controllable and switchable fiber pulse laser point towards a suitable solution for developing versatile pulse laser seed sources. This kind of source can potentially find a number of applications both in Q-switching and mode-locking regimes (for example, remote sensing, distance measurement, time-resolved spectroscopy, optical frequency metrology, or photo-acoustic imaging). This concept can be further expanded to an optical fiber taper that potentially provides more tight confinement of light, resulting in reduced device size with the higher operating speed of the device. The proposed scheme can also be applied to the plastic optical waveguides combined with an ionic gel, paving a novel way for actively controlled, flexible photonic devices. Based on this and combined with the fundamental studies, high repetition rate ultrafast fiber lasers or tunable repetition rate Q-switched fiber lasers also can be considered for future works. These investigations of graphene and CNT for externally controlled fiber lasers are also exciting to explore other LD SAs, especially 2D SAs, to find efficient optical devices with high performance and precisely tunable functionalities. 
(a)
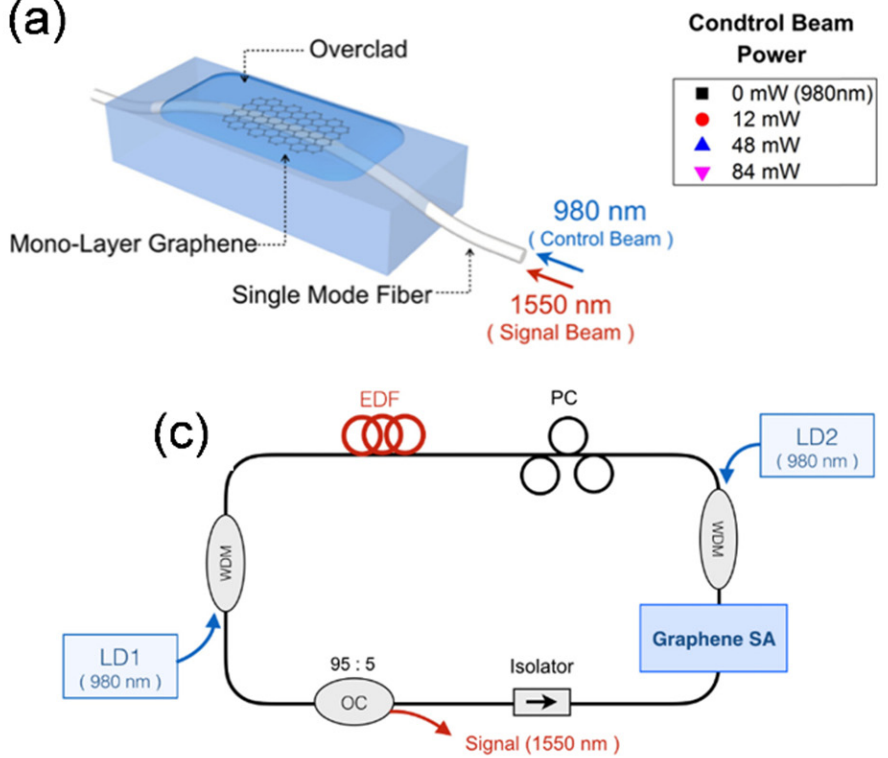

(b)

TE mode
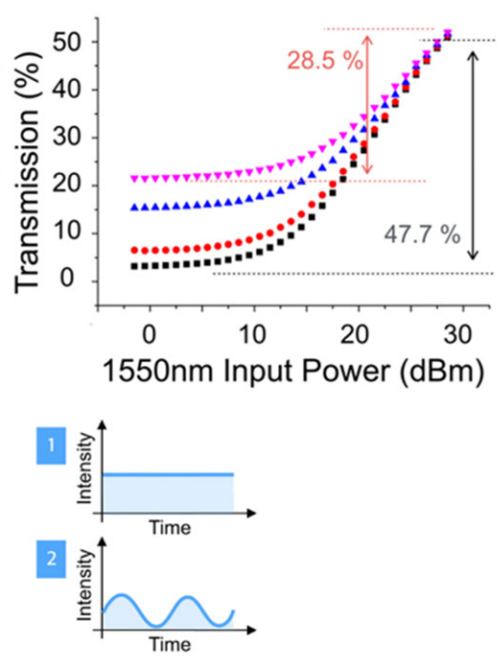

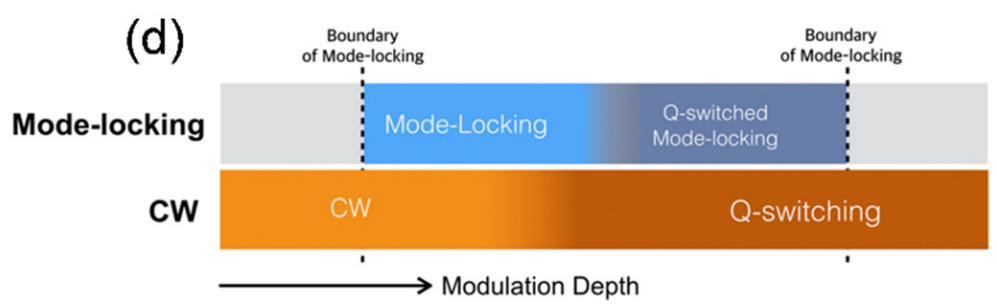

(e)

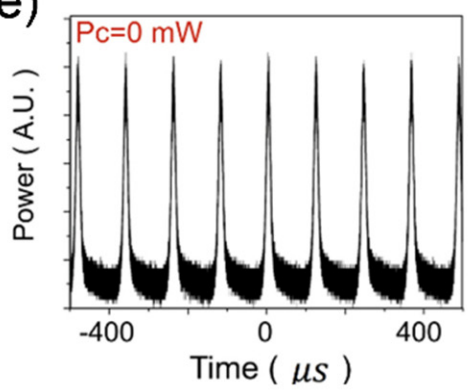

(f)

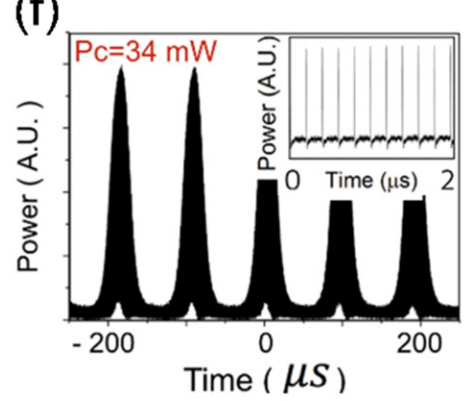

(g)

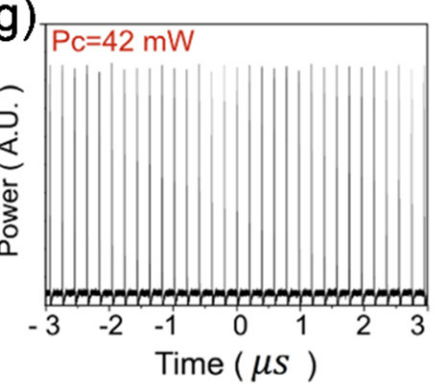

Figure 13. Optically controlled in-line graphene SA-based pulsed fiber laser (a) Schematic representation of optically tunable graphene SA. (b) Nonlinear transmission test result of the CW signal beam (1550 nm) TE mode variable with $\mathrm{CW}$ control beam powers at $980 \mathrm{~nm}$. (c) Illustration of Er-doped fiber ring laser incorporated with optically controllable in-line monolayer graphene SA device. LD: laser diode; EDF: erbium-doped fiber; PC: polarization controller; WDM: wavelength-division multiplexer and OC: optical coupler. (d) Schematic explanation of fiber laser operating regime as a function of modulation depth in graphene $\mathrm{SA},(\mathbf{e}) \mathrm{Q}$-switching operated pulse train with no control beam $\left(\mathrm{P}_{\mathrm{C}}=0 \mathrm{~mW}\right)$ applied, (f) Q-switched mode-locked operated pulse train with a control beam power of $34 \mathrm{~mW}$ (inset: an extended view of the pulse train in time scale) and (g) pulse train of CW mode-locked operation with a control beam power of $42 \mathrm{~mW}$. Reproduced with permission. Copyright 2016, OSA [68].

\section{Prospects for Future Research Directions}

Low-dimensional materials, particularly 2D materials, are a rising and hot topic expanding in quality, variety, and quantity. Over the last decade, the development of pulsed lasers based on LD materials has progressed rapidly, yielding many significant results and being employed in various applications. This is due to the reliability of synthesis of LD materials, coupling technology to implement SA devices, and the steady advancement of pulsed fiber laser technology over the decades. Nevertheless, there are still numerous 
challenges to realize high performance and finely tunable pulsed fiber laser and technical as well as scientific issues to be solved. Controllability of fiber laser in between Q-switching and mode-locking has been achieved by electrically and/or optically tuning the Fermi level, the modulation depth, and cross absorption modulation of LD materials. However, in the case of ion-liquid over-cladding, the switching speed and stability are limited by the ionic mobility in the ion liquid. This prospects towards the development of stable over-cladding in the capacitor structure based on LD SA on SPF that will benefit the stability and specifically control the mode-locking regime. Numerous stable over-cladding indexes and solid polymer indexes have been developed to study and analyze the LD SA-based mode-locked fiber laser and photonics characteristics. However, the externally controlled or gate-tunable LD SA-based fiber laser has not been studied yet, employing the stable over-cladding index required for enhanced coupling as well as for the EDL formation, which is crucial for the Fermi level tuning in the LD SAs. Moreover, only 2D graphene and 1D CNT among a large variety of LD SAs has been investigated for a tunable mode-locked fiber laser. There are many other LD SAs to be analyzed in this specific field for a stable, high-performance controllable fiber laser. Additionally, the basic characteristics of the ultrafast fiber laser, such as repetition rate and pulse duration, may be effectively controlled utilizing the tunable behavior of LD SA upon external (electrical and optical) bias. All of these LD-based tunable devices could also be investigated for various in-line all-fiber devices, such as ultrafast all-optical tunable switchers, optical limiters, all-optical modulators, polarizers etc., based on electrically/optically controlled nonlinear optical properties (i.e., higher-order susceptibility/nonlinearity, multiphoton absorption, etc.). The twist-angle in Bi-layer LD materials also can be engineered along with the externally (electrically and/or optically) controlled scheme to find the enhanced higher-order optical nonlinearity and SA properties for high performance, ultrafast and precisely controlled fiber lasers, and other nonlinear optical devices [54]. LD SA-based fs mode-locked ultrafast fiber lasers have grown emerging interest in space-borne applications, as they can sustain more than the life span of satellites $[136,208,209]$. Other radiation environments such as particle accelerators and radiation-based medical instruments also could be benefit from utilizing the controllable functionality of ultrafast fiber lasers based on actively controlled characteristics of LD SAs. The tunability of such fiber lasers could provide significant functionality in that application for the development of future space technology and many other advanced applications.

\section{Conclusions}

In conclusion, we present a brief review of numerous LD SA-based ultrafast fiber lasers and their performance reported so far in various technical schemes. Based on the aforementioned review, we estimate that LD materials with broadband optical response, high stability, good reliability, excellent thermal performance, low defects, and precisely controllable properties, which are compatible for high-energy ultrafast fiber laser along with the functional operation, will be constructed and taken out of the laboratory for realworld applications. Although there have been several reports on the electrically controlled nonlinear transmission and saturable absorption in graphene and carbon nanotube-based mode-locked ultrafast fiber laser and Q-switched laser, there is still more room to explore externally controlled saturable absorbers based on other LD SAs. The electrical and optical gating of graphene and SWCNT exposes the opportunities for the development of externally (electrically or optically) tunable other various LD-materials based nonlinear optical devices and points towards advanced device performances with tunable nonlinearity and controllable functionalities. Principally in both practical and theoretical frameworks, the externally (electrically and/or optically) tunable nonlinear optical operation of 2D graphene and other LD nonlinear optical materials also propose a variety of technical and scientific benefits, such as devices with a compact minimum footprint, exceedingly fast speed (more than a few tens of GHz), chip-scale integration and compatibility with complementary metal-oxide-semiconductor (CMOS) technology, all of which are required 
ideal standards for future on-chip photonic and optoelectronic applications. These will also benefit the basic study and investigation of LD materials for further understanding the incomparable advantages of nonlinear optical as well as ultrafast photonic systems over their electronic counterparts.

Author Contributions: Conceptualization, P.C.D. and D.-I.Y., Methodology, P.C.D. and D.-I.Y., Data collection P.C.D., Writing P.C.D. and D.-I.Y. All authors have read and agreed to the published version of the manuscript.

Funding: This work was supported by Brain Pool Program through the National Research Foundation of Korea (NRF) funded by the Ministry of Science and ICT (NRF-2019H1D3A1A02071061).

Institutional Review Board Statement: Not applicable.

Informed Consent Statement: Not applicable.

Data Availability Statement: Data is contained within the article which are from various articles cited as references.

Conflicts of Interest: The authors declare no conflict of interest.

\section{References}

1. Chou, S.Y.; Keimel, C.; Gu, J. Ultrafast and direct imprint of nanostructures in silicon. Nature 2002, 417, 835-837. [CrossRef]

2. Ma, J.; Xie, G.Q.; Gao, W.L.; Yuan, P.; Qian, L.J.; Yu, H.H.; Zhang, H.J.; Wang, J.Y. Diode-pumped mode-locked femtosecond Tm:CLNGG disordered crystal laser. Opt. Lett. 2012, 37, 1376-1378. [CrossRef]

3. Kondo, Y.; Nouchi, K.; Mitsuyu, T.; Watanabe, M.; Kazansky, P.G.; Hirao, K. Fabrication of long-period fiber gratings by focused irradiation of infrared femtosecond laser pulses. Opt. Lett. 1999, 24, 646-648. [CrossRef]

4. Marcinkevi Ius, A.; Juodkazis, S.; Watanabe, M.; Miwa, M.; Matsuo, S.; Misawa, H.; Nishii, J. Femtosecond laser-assisted three-dimensional microfabrication in silica. Opt. Lett. 2001, 26, 277-279. [CrossRef]

5. Schaffer, C.B.; Brodeur, A.; García, J.F.; Mazur, E. Micromachining bulk glass by use of femtosecond laser pulses with nanojoule energy. Opt. Lett. 2001, 26, 93-95. [CrossRef]

6. Keller, U. Recent developments in compact ultrafast lasers. Nature 2003, 424, 831-838. [CrossRef]

7. Fermann, M.E.; Hartl, I. Ultrafast fibre lasers. Nat. Photonics 2013, 7, 868-874. [CrossRef]

8. Guo, B.; Xiao, Q.-1.; Wang, S.-h.; Zhang, H. 2D Layered Materials: Synthesis, Nonlinear Optical Properties, and Device Applications. Laser Photonics Rev. 2019, 13, 1800327. [CrossRef]

9. He, J.; Tao, L.; Zhang, H.; Zhou, B.; Li, J. Emerging 2D materials beyond graphene for ultrashort pulse generation in fiber lasers. Nanoscale 2019, 11, 2577-2593. [CrossRef] [PubMed]

10. Okhotnikov, O.; Jouhti, T.; Konttinen, J.; Karirinne, S.; Pessa, M. 1.5- $\mu$ m monolithic GaInNAs semiconductor saturable-absorber mode locking of an erbium fiber laser. Opt. Lett. 2003, 28, 364-366. [CrossRef] [PubMed]

11. Aguergaray, C.; Broderick, N.G.R.; Erkintalo, M.; Chen, J.S.Y; Kruglov, V. Mode-locked femtosecond all-normal all-PM Yb-doped fiber laser using a nonlinear amplifying loop mirror. Opt. Express 2012, 20, 10545-10551. [CrossRef]

12. Liu, X.; Zhan, L.; Luo, S.; Gu, Z.; Liu, J.; Wang, Y.; Shen, Q. Multiwavelength erbium-doped fiber laser based on a nonlinear amplifying loop mirror assisted by un-pumped EDF. Opt. Express 2012, 20, 7088-7094. [CrossRef] [PubMed]

13. Matsas, V.; Newson, T.; Richardson, D.; Payne, D.N. Self-starting, passively mode-locked fibre ring soliton laser exploiting non-linear polarisation rotation. Electron. Lett. 1992, 28, 1391-1393. [CrossRef]

14. Wei, C.; Shi, H.; Luo, H.; Zhang, H.; Lyu, Y.; Liu, Y. $34 \mathrm{~nm}$-wavelength-tunable picosecond $\mathrm{Ho}^{3+} / \mathrm{Pr}^{3+}$-codoped ZBLAN fiber laser. Opt. Express 2017, 25, 19170-19178. [CrossRef] [PubMed]

15. Gluth, A.; Wang, Y.; Petrov, V.; Paajaste, J.; Suomalainen, S.; Härkönen, A.; Guina, M.; Steinmeyer, G.; Mateos, X.; Veronesi, S. GaSb-based SESAM mode-locked Tm: YAG ceramic laser at $2 \mu \mathrm{m}$. Opt. Express 2015, 23, 1361-1369. [CrossRef] [PubMed]

16. Keller, U.; Weingarten, K.J; Kartner, F.X.; Kopf, D.; Braun, B.; Jung, I.D.; Fluck, R.; Honninger, C.; Matuschek, N.; Der Au, J.A. Semiconductor saturable absorber mirrors (SESAM's) for femtosecond to nanosecond pulse generation in solid-state lasers. IEEE J. Sel. Top. Quantum Electron. 1996, 2, 435-453. [CrossRef]

17. Keller, U.; Miller, D.; Boyd, G.; Chiu, T.; Ferguson, J.; Asom, M. Solid-state low-loss intracavity saturable absorber for Nd: YLF lasers: An antiresonant semiconductor Fabry-Perot saturable absorber. Opt. Lett. 1992, 17, 505-507. [CrossRef]

18. Okhotnikov, O.; Grudinin, A.; Pessa, M. Ultra-fast fibre laser systems based on SESAM technology: New horizons and applications. New J. Phys. 2004, 6, 177. [CrossRef]

19. Tang, P.; Qin, Z.; Liu, J.; Zhao, C.; Xie, G.; Wen, S.; Qian, L. Watt-level passively mode-locked Er3+-doped ZBLAN fiber laser at $2.8 \mu \mathrm{m}$. Opt. Lett. 2015, 40, 4855-4858. [CrossRef]

20. Sun, Z.; Hasan, T.; Torrisi, F.; Popa, D.; Privitera, G.; Wang, F.; Bonaccorso, F.; Basko, D.M.; Ferrari, A.C. Graphene mode-locked ultrafast laser. ACS Nano 2010, 4, 803-810. [CrossRef] 
21. Bao, Q.; Zhang, H.; Wang, Y.; Ni, Z.; Yan, Y.; Shen, Z.X.; Loh, K.P.; Tang, D.Y. Atomic-layer graphene as a saturable absorber for ultrafast pulsed lasers. Adv. Funct. Mater. 2009, 19, 3077-3083. [CrossRef]

22. Yamashita, S.; Inoue, Y.; Maruyama, S.; Murakami, Y.; Yaguchi, H.; Jablonski, M.; Set, S. Saturable absorbers incorporating carbon nanotubes directly synthesized onto substrates and fibers and their application to mode-locked fiber lasers. Opt. Lett. 2004, 29, 1581-1583. [CrossRef] [PubMed]

23. Hasan, T.; Sun, Z.; Wang, F.; Bonaccorso, F.; Tan, P.H.; Rozhin, A.G.; Ferrari, A.C. Nanotube-polymer composites for ultrafast photonics. Adv. Mater. 2009, 21, 3874-3899. [CrossRef]

24. Du, J.; Zhang, M.; Guo, Z.; Chen, J.; Zhu, X.; Hu, G.; Peng, P.; Zheng, Z.; Zhang, H. Phosphorene quantum dot saturable absorbers for ultrafast fiber lasers. Sci. Rep. 2017, 7, 42357. [CrossRef] [PubMed]

25. Lee, E.J.; Choi, S.Y.; Jeong, H.; Park, N.H.; Yim, W.; Kim, M.H.; Park, J.K.; Son, S.; Bae, S.; Kim, S.J.; et al. Active control of all-fibre graphene devices with electrical gating. Nat. Commun. 2015, 6, 6851. [CrossRef] [PubMed]

26. Bogusławski, J.; Wang, Y.; Xue, H.; Yang, X.; Mao, D.; Gan, X.; Ren, Z.; Zhao, J.; Dai, Q.; Soboń, G.; et al. Graphene Actively Mode-Locked Lasers. Adv. Funct. Mater. 2018, 28, 1801539. [CrossRef]

27. Li, D.; Xue, H.; Qi, M.; Wang, Y.; Aksimsek, S.; Chekurov, N.; Kim, W.; Li, C.; Riikonen, J.; Ye, F.; et al. Graphene actively Q-switched lasers. 2D Mater. 2017, 4, 025095. [CrossRef]

28. Lee, J.; Koo, J.; Chang, Y.M.; Debnath, P.; Song, Y.-W.; Lee, J.H. Experimental investigation on a Q-switched, mode-locked fiber laser based on the combination of active mode locking and passive $Q$ switching. J. Opt. Soc. Am. B 2012, 29, 1479-1485. [CrossRef]

29. Xia, H.; Li, H.; Lan, C.; Li, C.; Zhang, X.; Zhang, S.; Liu, Y. Erbium-doped fiber laser mode-locked with a few-layer MoS 2 saturable absorber. In Proceedings of the Asia Communications and Photonics Conference, Optical Society of America, Shanghai, China, 11-14 November 2014; p. ATh3A. 89.

30. Liu, H.; Zheng, X.W.; Liu, M.; Zhao, N.; Luo, A.P.; Luo, Z.C.; Xu, W.C.; Zhang, H.; Zhao, C.J.; Wen, S.C. Femtosecond pulse generation from a topological insulator mode-locked fiber laser. Opt. Express 2014, 22, 6868-6873. [CrossRef] [PubMed]

31. Bonaccorso, F.; Sun, Z.; Hasan, T.; Ferrari, A. Graphene photonics and optoelectronics. Nat. Photonics 2010, 4, 611. [CrossRef]

32. Debnath, P.C.; Park, J.; Scott, A.M.; Lee, J.; Lee, J.H.; Song, Y.W. In situ synthesis of graphene with telecommunication lasers for nonlinear optical devices. Adv. Opt. Mater. 2015, 3, 1264-1272. [CrossRef]

33. Jhon, Y.I.; Koo, J.; Anasori, B.; Seo, M.; Lee, J.H.; Gogotsi, Y.; Jhon, Y.M. Metallic MXene saturable absorber for femtosecond mode-locked lasers. Adv. Mater. 2017, 29, 1702496. [CrossRef] [PubMed]

34. Yi, Y.; Sun, Z.; Li, J.; Chu, P.K.; Yu, X.F. Optical and optoelectronic properties of black phosphorus and recent photonic and optoelectronic applications. Small Methods 2019, 3, 1900165. [CrossRef]

35. Debnath, P.C.; Park, K.; Song, Y.W. Recent Advances in Black-Phosphorus-Based Photonics and Optoelectronics Devices. Small Methods 2018, 2, 1700315. [CrossRef]

36. Lee, D.; Park, K.; Debnath, P.C.; Kim, I.; Song, Y.W. Thermal damage suppression of a black phosphorus saturable absorber for high-power operation of pulsed fiber lasers. Nanotechnology 2016, 27, 365203. [CrossRef] [PubMed]

37. Aktürk, E.; Aktürk, O.Ü.; Ciraci, S. Single and bilayer bismuthene: Stability at high temperature and mechanical and electronic properties. Phys. Rev. B 2016, 94, 014115. [CrossRef]

38. Dresselhaus, M.S.; Dresselhaus, G.; Eklund, P.C. Science of Fullerenes and Carbon Nanotubes: Their Properties and Applications; Elsevier: Amsterdam, The Netherlands, 1996.

39. Mak, K.F.; Lee, C.; Hone, J.; Shan, J.; Heinz, T.F. Atomically Thin $\mathrm{MoS}_{2}$ : A New Direct-Gap Semiconductor. Phys. Rev. Lett. 2010, 105, 136805. [CrossRef]

40. Nair, R.R.; Blake, P.; Grigorenko, A.N.; Novoselov, K.S.; Booth, T.J.; Stauber, T.; Peres, N.M.; Geim, A.K. Fine structure constant defines visual transparency of graphene. Science 2008, 320, 1308. [CrossRef]

41. Geim, A.K. Graphene: Status and Prospects. Science 2009, 324, 1530-1534. [CrossRef]

42. Geim, A.K.; Novoselov, K.S. The rise of graphene. Nat. Mater. 2007, 6, 183-191. [CrossRef]

43. Novoselov, K.S.; Fal, V.; Colombo, L.; Gellert, P.; Schwab, M.; Kim, K. A roadmap for graphene. Nature 2012, $490,192-200$. [CrossRef] [PubMed]

44. Novoselov, K.S.; Geim, A.K.; Morozov, S.V.; Jiang, D.; Katsnelson, M.I.; Grigorieva, I.; Dubonos, S.; Firsov, A. Two-dimensional gas of massless Dirac fermions in graphene. Nature 2005, 438, 197-200. [CrossRef]

45. Novoselov, K.S.; Geim, A.K.; Morozov, S.V.; Jiang, D.; Zhang, Y.; Dubonos, S.V.; Grigorieva, I.V.; Firsov, A.A. Electric field effect in atomically thin carbon films. Science 2004, 306, 666-669. [CrossRef] [PubMed]

46. Lu, L.; Wang, W.; Wu, L.; Jiang, X.; Xiang, Y.; Li, J.; Fan, D.; Zhang, H. All-Optical Switching of Two Continuous Waves in Few Layer Bismuthene Based on Spatial Cross-Phase Modulation. ACS Photonics 2017, 4, 2852-2861. [CrossRef]

47. Singh, D.; Gupta, S.K.; Sonvane, Y.; Lukačević, I. Antimonene: A monolayer material for ultraviolet optical nanodevices. J. Mater. Chem. C 2016, 4, 6386-6390. [CrossRef]

48. Lu, S.B.; Miao, L.L.; Guo, Z.N.; Qi, X.; Zhao, C.J.; Zhang, H.; Wen, S.C.; Tang, D.Y.; Fan, D.Y. Broadband nonlinear optical response in multi-layer black phosphorus: An emerging infrared and mid-infrared optical material. Opt. Express 2015, 23, 11183-11194. [CrossRef]

49. Wang, Q.H.; Kalantar-Zadeh, K.; Kis, A.; Coleman, J.N.; Strano, M.S. Electronics and optoelectronics of two-dimensional transition metal dichalcogenides. Nat. Nanotechnol. 2012, 7, 699-712. [CrossRef] 
50. Hanlon, D.; Backes, C.; Doherty, E.; Cucinotta, C.S.; Berner, N.C.; Boland, C.; Lee, K.; Harvey, A.; Lynch, P.; Gholamvand, Z.; et al. Liquid exfoliation of solvent-stabilized few-layer black phosphorus for applications beyond electronics. Nat. Commun. 2015, 6, 8563. [CrossRef]

51. Koppens, F.H.L.; Mueller, T.; Avouris, P.; Ferrari, A.C.; Vitiello, M.S.; Polini, M. Photodetectors based on graphene, other two-dimensional materials and hybrid systems. Nat. Nanotechnol. 2014, 9, 780-793. [CrossRef]

52. Wu, K.; Wang, Y.; Qiu, C.; Chen, J. Thermo-optic all-optical devices based on two-dimensional materials. Photonics Res. 2018, 6, C22-C28. [CrossRef]

53. Wu, K.; Chen, B.; Zhang, X.; Zhang, S.; Guo, C.; Li, C.; Xiao, P.; Wang, J.; Zhou, L.; Zou, W. High-performance mode-locked and Q-switched fiber lasers based on novel 2D materials of topological insulators, transition metal dichalcogenides and black phosphorus: Review and perspective. Opt. Commun. 2018, 406, 214-229. [CrossRef]

54. Ha, S.; Park, N.H.; Kim, H.; Shin, J.; Choi, J.; Park, S.; Moon, J.-Y.; Chae, K.; Jung, J.; Lee, J.-H. Enhanced third-harmonic generation by manipulating the twist angle of bilayer graphene. Light Sci. Appl. 2021, 10, 1-10. [CrossRef] [PubMed]

55. Hsu, W.-T.; Zhao, Z.-A.; Li, L.-J.; Chen, C.-H.; Chiu, M.-H.; Chang, P.-S.; Chou, Y.-C.; Chang, W.-H. Second harmonic generation from artificially stacked transition metal dichalcogenide twisted bilayers. ACS Nano 2014, 8, 2951-2958. [CrossRef] [PubMed]

56. Li, J.; Zhang, Z.; Du, L.; Miao, L.; Yi, J.; Huang, B.; Zou, Y.; Zhao, C.; Wen, S. Highly stable femtosecond pulse generation from a MXene $\mathrm{Ti}_{3} \mathrm{C}_{2} \mathrm{~T}_{\mathrm{x}}(\mathrm{T}=\mathrm{F}, \mathrm{O}$, or $\mathrm{OH})$ mode-locked fiber laser. Photonics Res. 2019, 7, 260-264. [CrossRef]

57. Hao, Q.; Wang, C.; Liu, W.; Liu, X.; Liu, J.; Zhang, H. Low-dimensional saturable absorbers for ultrafast photonics in solid-state bulk lasers: Status and prospects. Nanophotonics 2020, 9, 2603-2639. [CrossRef]

58. Wang, J.; Wang, X.; Lei, J.; Ma, M.; Wang, C.; Ge, Y.; Wei, Z. Recent advances in mode-locked fiber lasers based on two-dimensional materials. Nanophotonics 2020, 9, 2315-2340. [CrossRef]

59. Im, J.H.; Choi, S.Y.; Rotermund, F.; Yeom, D.I. All-fiber Er-doped dissipative soliton laser based on evanescent field interaction with carbon nanotube saturable absorber. Opt. Express 2010, 18, 22141-22146. [CrossRef]

60. Jeong, H.; Choi, S.Y.; Rotermund, F.; Cha, Y.-H.; Jeong, D.-Y.; Yeom, D.-I. All-fiber mode-locked laser oscillator with pulse energy of $34 \mathrm{~nJ}$ using a single-walled carbon nanotube saturable absorber. Opt. Express 2014, 22, 22667-22672. [CrossRef]

61. Jeong, H.; Choi, S.Y.; Rotermund, F.; Lee, K.; Yeom, D.-I. All-polarization maintaining passively mode-locked fiber laser using evanescent field interaction with single-walled carbon nanotube saturable absorber. J. Lightwave Technol. 2016, 34, 3510-3514. [CrossRef]

62. Jeong, H.; Yeom, D.-I. Passively Q-switched Erbium Doped All-fiber Laser with High Pulse Energy Based on Evanescent Field Interaction with Single-walled Carbon Nanotube Saturable Absorber. Curr. Opt. Photonics 2017, 1, $203-206$.

63. Jeong, H.; Choi, S.Y.; Rotermund, F.; Yeom, D.I. Pulse width shaping of passively mode-locked soliton fiber laser via polarization control in carbon nanotube saturable absorber. Opt. Express 2013, 21, 27011-27016. [CrossRef]

64. Jeong, H.; Choi, S.Y.; Jeong, E.I.; Cha, S.J.; Rotermund, F.; Yeom, D.-I. Ultrafast mode-locked fiber laser using a waveguide-type saturable absorber based on single-walled carbon nanotubes. Appl. Phys. Express 2013, 6, 052705. [CrossRef]

65. Jiang, T.; Yin, K.; Wang, C.; You, J.; Ouyang, H.; Miao, R.; Zhang, C.; Wei, K.; Li, H.; Chen, H.; et al. Ultrafast fiber lasers mode-locked by two-dimensional materials: Review and prospect. Photonics Res. 2020, 8, 78-90. [CrossRef]

66. Kovalchuk, O.; Uddin, S.; Lee, S.; Song, Y.-W. Graphene Capacitor-Based Electrical Switching of Mode-Locking in All-Fiberized Femtosecond Lasers. ACS Appl. Mater. Interfaces 2020, 12, 54005-54011. [CrossRef] [PubMed]

67. Gladush, Y.; Mkrtchyan, A.A.; Kopylova, D.S.; Ivanenko, A.; Nyushkov, B.; Kobtsev, S.; Kokhanovskiy, A.; Khegai, A.; Melkumov, M.; Burdanova, M. Ionic liquid gated carbon nanotube saturable absorber for switchable pulse generation. Nano Lett. 2019, 19, 5836-5843. [CrossRef] [PubMed]

68. Gene, J.; Park, N.H.; Jeong, H.; Choi, S.Y.; Rotermund, F.; Yeom, D.I.; Kim, B.Y. Optically controlled in-line graphene saturable absorber for the manipulation of pulsed fiber laser operation. Opt. Express 2016, 24, 21301-21307. [CrossRef] [PubMed]

69. Kong, L.; Qin, Z.; Xie, G.; Guo, Z.; Zhang, H.; Yuan, P.; Qian, L. Black phosphorus as broadband saturable absorber for pulsed lasers from $1 \mu \mathrm{m}$ to $2.7 \mu \mathrm{m}$ wavelength. Laser Phys. Lett. 2016, 13, 045801. [CrossRef]

70. Jiang, Y.; Miao, L.; Jiang, G.; Chen, Y.; Qi, X.; Jiang, X.-f.; Zhang, H.; Wen, S. Broadband and enhanced nonlinear optical response of $\mathrm{MoS}_{2}$ /graphene nanocomposites for ultrafast photonics applications. Sci. Rep. 2015, 5, 16372. [CrossRef]

71. Fu, B.; Hua, Y.; Xiao, X.; Zhu, H.; Sun, Z.; Yang, C. Broadband graphene saturable absorber for pulsed fiber lasers at 1, 1.5, and $2 \mu \mathrm{m}$. IEEE J. Sel. Top. Quantum Electron. 2014, 20, 411-415.

72. Song, Y.-W.; Jang, S.-Y.; Han, W.-S.; Bae, M.-K. Graphene mode-lockers for fiber lasers functioned with evanescent field interaction. Appl. Phys. Lett. 2010, 96, 051122. [CrossRef]

73. Yamashita, S. A tutorial on nonlinear photonic applications of carbon nanotube and graphene. J. Lightwave Technol. 2011, 30, 427-447. [CrossRef]

74. Zhang, H.; He, X.; Lin, W.; Wei, R.; Zhang, F.; Du, X.; Dong, G.; Qiu, J. Ultrafast saturable absorption in topological insulator $\mathrm{Bi}_{2} \mathrm{SeTe}_{2}$ nanosheets. Opt. Express 2015, 23, 13376-13383. [CrossRef] [PubMed]

75. Zhang, H.; Virally, S.; Bao, Q.; Kian Ping, L.; Massar, S.; Godbout, N.; Kockaert, P. Z-scan measurement of the nonlinear refractive index of graphene. Opt. Lett. 2012, 37, 1856-1858. [CrossRef] [PubMed]

76. Zheng, X.; Zhang, Y.; Chen, R.; Cheng, X.a.; Xu, Z.; Jiang, T. Z-scan measurement of the nonlinear refractive index of monolayer $\mathrm{WS}_{2}$. Opt. Express 2015, 23, 15616-15623. [CrossRef] [PubMed] 
77. Wang, G.; Wang, K.; Szydłowska, B.M.; Baker-Murray, A.A.; Wang, J.J.; Feng, Y.; Zhang, X.; Wang, J.; Blau, W.J. Ultrafast Nonlinear Optical Properties of a Graphene Saturable Mirror in the $2 \mu \mathrm{m}$ Wavelength Region. Laser Photonics Rev. 2017, 11, 1700166. [CrossRef]

78. Chhowalla, M.; Shin, H.S.; Eda, G.; Li, L.-J.; Loh, K.P.; Zhang, H. The chemistry of two-dimensional layered transition metal dichalcogenide nanosheets. Nat. Chem. 2013, 5, 263-275. [CrossRef]

79. Ugeda, M.M.; Bradley, A.J.; Shi, S.-F.; da Jornada, F.H.; Zhang, Y.; Qiu, D.Y.; Ruan, W.; Mo, S.-K.; Hussain, Z.; Shen, Z.-X.; et al. Giant bandgap renormalization and excitonic effects in a monolayer transition metal dichalcogenide semiconductor. Nat. Mater. 2014, 13, 1091-1095. [CrossRef]

80. Lee, J.; Koo, J.; Lee, J.; Jhon, Y.M.; Lee, J.H. All-fiberized, femtosecond laser at $1912 \mathrm{~nm}$ using a bulk-like MoSe 2 saturable absorber. Opt. Mater. Express 2017, 7, 2968-2979. [CrossRef]

81. Cui, Y.; Lu, F.; Liu, X. Nonlinear Saturable and Polarization-induced Absorption of Rhenium Disulfide. Sci. Rep. 2017, 7, 40080. [CrossRef]

82. Wang, G.; Baker-Murray, A.A.; Blau, W.J. Saturable Absorption in 2D Nanomaterials and Related Photonic Devices. Laser Photonics Rev. 2019, 13, 1800282. [CrossRef]

83. Castellanos-Gomez, A.; Vicarelli, L.; Prada, E.; Island, J.O.; Narasimha-Acharya, K.; Blanter, S.I.; Groenendijk, D.J.; Buscema, M.; Steele, G.A.; Alvarez, J. Isolation and characterization of few-layer black phosphorus. 2D Mater. 2014, 1, 025001. [CrossRef]

84. Xia, F.; Wang, H.; Jia, Y. Rediscovering black phosphorus as an anisotropic layered material for optoelectronics and electronics. Nat. Commun. 2014, 5, 4458. [CrossRef] [PubMed]

85. Sotor, J.; Sobon, G.; Macherzynski, W.; Paletko, P.; Abramski, K.M. Black phosphorus saturable absorber for ultrashort pulse generation. Appl. Phys. Lett. 2015, 107, 051108. [CrossRef]

86. Li, L.; Yu, Y.; Ye, G.J.; Ge, Q.; Ou, X.; Wu, H.; Feng, D.; Chen, X.H.; Zhang, Y. Black phosphorus field-effect transistors. Nat. Nanotechnol. 2014, 9, 372-377. [CrossRef] [PubMed]

87. Tran, V.; Soklaski, R.; Liang, Y.; Yang, L. Layer-controlled band gap and anisotropic excitons in few-layer black phosphorus. Phys. Rev. B 2014, 89, 235319. [CrossRef]

88. Liu, J.; Liu, J.; Guo, Z.; Zhang, H.; Ma, W.; Wang, J.; Su, L. Dual-wavelength Q-switched Er:SrF 2 laser with a black phosphorus absorber in the mid-infrared region. Opt. Express 2016, 24, 30289-30295. [CrossRef] [PubMed]

89. Wang, K.; Szydłowska, B.M.; Wang, G.; Zhang, X.; Wang, J.J.; Magan, J.J.; Zhang, L.; Coleman, J.N.; Wang, J.; Blau, W.J. Ultrafast Nonlinear Excitation Dynamics of Black Phosphorus Nanosheets from Visible to Mid-Infrared. ACS Nano 2016, 10, 6923-6932. [CrossRef] [PubMed]

90. Na, D.; Park, K.; Park, K.-H.; Song, Y.-W. Passivation of black phosphorus saturable absorbers for reliable pulse formation of fiber lasers. Nanotechnology 2017, 28, 475207. [CrossRef]

91. Moore, J.E. The birth of topological insulators. Nature 2010, 464, 194-198. [CrossRef]

92. Hasan, M.Z.; Kane, C.L. Colloquium: Topological insulators. Rev. Mod. Phys. 2010, 82, 3045-3067. [CrossRef]

93. Zhang, H.; Liu, C.-X.; Qi, X.-L.; Dai, X.; Fang, Z.; Zhang, S.-C. Topological insulators in $\mathrm{Bi}_{2} \mathrm{Se}_{3}, \mathrm{Bi}_{2} \mathrm{Te}_{3}$ and $\mathrm{Sb}_{2} \mathrm{Te}_{3}$ with a single Dirac cone on the surface. Nat. Phys. 2009, 5, 438-442. [CrossRef]

94. Naguib, M.; Come, J.; Dyatkin, B.; Presser, V.; Taberna, P.-L.; Simon, P.; Barsoum, M.W.; Gogotsi, Y. MXene: A promising transition metal carbide anode for lithium-ion batteries. Electrochem. Commun. 2012, 16, 61-64. [CrossRef]

95. Naguib, M.; Mochalin, V.N.; Barsoum, M.W.; Gogotsi, Y. 25th Anniversary Article: MXenes: A New Family of Two-Dimensional Materials. Adv. Mater. 2014, 26, 992-1005. [CrossRef] [PubMed]

96. Liu, M.-Y.; Huang, Y.; Chen, Q.-Y.; Li, Z.-Y.; Cao, C.; He, Y. Strain and electric field tunable electronic structure of buckled bismuthene. RSC Adv. 2017, 7, 39546-39555. [CrossRef]

97. Pumera, M.; Sofer, Z. 2D Monoelemental Arsenene, Antimonene, and Bismuthene: Beyond Black Phosphorus. Adv. Mater. 2017, 29, 1605299. [CrossRef]

98. Song, Y.; Liang, Z.; Jiang, X.; Chen, Y.; Li, Z.; Lu, L.; Ge, Y.; Wang, K.; Zheng, J.; Lu, S. Few-layer antimonene decorated microfiber: Ultra-short pulse generation and all-optical thresholding with enhanced long term stability. 2D Mater. 2017, 4, 045010. [CrossRef]

99. Hong, S.; Lédée, F.; Park, J.; Song, S.; Lee, H.; Lee, Y.S.; Kim, B.; Yeom, D.I.; Deleporte, E.; Oh, K. Mode-Locking of All-Fiber Lasers Operating at Both Anomalous and Normal Dispersion Regimes in the C-and L-Bands Using Thin Film of 2D Perovskite Crystallites. Laser Photonics Rev. 2018, 12, 1800118. [CrossRef]

100. Liu, Z.; Mu, H.; Xiao, S.; Wang, R.; Wang, Z.; Wang, W.; Wang, Y.; Zhu, X.; Lu, K.; Zhang, H.; et al. Pulsed Lasers Employing Solution-Processed Plasmonic $\mathrm{Cu}_{3-\mathrm{x}}$ P Colloidal Nanocrystals. Adv. Mater. 2016, 28, 3535-3542. [CrossRef] [PubMed]

101. Lee, S.; Song, Y.-W. Graphene Self-Phase-Lockers Formed around a Cu Wire Hub for Ring Resonators Incorporated into 57.8 Gigahertz Fiber Pulsed Lasers. ACS Nano 2020, 14, 15944-15952. [CrossRef]

102. Wang, Y.; Mu, H.; Li, X.; Yuan, J.; Chen, J.; Xiao, S.; Bao, Q.; Gao, Y.; He, J. Observation of large nonlinear responses in a graphene- $\mathrm{Bi}_{2} \mathrm{Te}_{3}$ heterostructure at a telecommunication wavelength. Appl. Phys. Lett. 2016, 108, 221901. [CrossRef]

103. Frisenda, R.; Navarro-Moratalla, E.; Gant, P.; Pérez De Lara, D.; Jarillo-Herrero, P.; Gorbachev, R.V.; Castellanos-Gomez, A. Recent progress in the assembly of nanodevices and van der Waals heterostructures by deterministic placement of 2D materials. Chem. Soc. Rev. 2018, 47, 53-68. [CrossRef] 
104. Wang, Z.; Mu, H.; Yuan, J.; Zhao, C.; Bao, Q.; Zhang, H. Graphene-Bi $\mathrm{Te}_{3}$ heterostructure as broadband saturable absorber for ultra-short pulse generation in Er-doped and Yb-doped fiber lasers. IEEE J. Sel. Top. Quantum Electron. 2016, 23, 195-199. [CrossRef]

105. Chen, H.; Yin, J.; Yang, J.; Zhang, X.; Liu, M.; Jiang, Z.; Wang, J.; Sun, Z.; Guo, T.; Liu, W.; et al. Transition-metal dichalcogenides heterostructure saturable absorbers for ultrafast photonics. Opt. Lett. 2017, 42, 4279-4282. [CrossRef]

106. Ostojic, G.N.; Zaric, S.; Kono, J.; Strano, M.S.; Moore, V.C.; Hauge, R.H.; Smalley, R.E. Interband Recombination Dynamics in Resonantly Excited Single-Walled Carbon Nanotubes. Phys. Rev. Lett. 2004, 92, 117402. [CrossRef] [PubMed]

107. Lee, J.; Koo, J.; Jhon, Y.M.; Lee, J.H. A femtosecond pulse erbium fiber laser incorporating a saturable absorber based on bulk-structured $\mathrm{Bi}_{2} \mathrm{Te}_{3}$ topological insulator. Opt. Express 2014, 22, 6165-6173. [CrossRef] [PubMed]

108. Jung, M.; Lee, J.; Koo, J.; Park, J.; Song, Y.-W.; Lee, K.; Lee, S.; Lee, J.H. A femtosecond pulse fiber laser at 1935 nm using a bulk-structured $\mathrm{Bi}_{2} \mathrm{Te}_{3}$ topological insulator. Opt. Express 2014, 22, 7865-7874. [CrossRef] [PubMed]

109. Li, H.; Lu, G.; Wang, Y.; Yin, Z.; Cong, C.; He, Q.; Wang, L.; Ding, F.; Yu, T.; Zhang, H. Mechanical Exfoliation and Characterization of Single- and Few-Layer Nanosheets of $\mathrm{WSe}_{2}, \mathrm{TaS}_{2}$, and TaSe 2 . Small 2013, 9, 1974-1981. [CrossRef]

110. Chen, Y.; Jiang, G.; Chen, S.; Guo, Z.; Yu, X.; Zhao, C.; Zhang, H.; Bao, Q.; Wen, S.; Tang, D.; et al. Mechanically exfoliated black phosphorus as a new saturable absorber for both Q-switching and Mode-locking laser operation. Opt. Express 2015, 23, 12823-12833. [CrossRef]

111. Wang, Z.; Jia, H.; Zheng, X.; Yang, R.; Wang, Z.; Ye, G.; Chen, X.; Shan, J.; Feng, P.X.-L. Black phosphorus nanoelectromechanical resonators vibrating at very high frequencies. Nanoscale 2015, 7, 877-884. [CrossRef] [PubMed]

112. Nicolosi, V.; Chhowalla, M.; Kanatzidis, M.G.; Strano, M.S.; Coleman, J.N. Liquid exfoliation of layered materials. Science 2013, 340, 6139. [CrossRef]

113. Aiub, E.J.; Steinberg, D.; de Souza, E.A.T.; Saito, L.A. 200-fs mode-locked Erbium-doped fiber laser by using mechanically exfoliated $\mathrm{MoS}_{2}$ saturable absorber onto D-shaped optical fiber. Opt. Express 2017, 25, 10546-10552. [CrossRef]

114. Luo, Z.-C.; Liu, M.; Guo, Z.-N.; Jiang, X.-F.; Luo, A.-P.; Zhao, C.-J.; Yu, X.-F.; Xu, W.-C.; Zhang, H. Microfiber-based few-layer black phosphorus saturable absorber for ultra-fast fiber laser. Opt. Express 2015, 23, 20030-20039. [CrossRef]

115. Li, X.; Cai, W.; An, J.; Kim, S.; Nah, J.; Yang, D.; Piner, R.; Velamakanni, A.; Jung, I.; Tutuc, E. Large-area synthesis of high-quality and uniform graphene films on copper foils. Science 2009, 324, 1312-1314. [CrossRef]

116. Liu, W.; Liu, M.; Yin, J.; Chen, H.; Lu, W.; Fang, S.; Teng, H.; Lei, M.; Yan, P.; Wei, Z. Tungsten diselenide for all-fiber lasers with the chemical vapor deposition method. Nanoscale 2018, 10, 7971-7977. [CrossRef]

117. Yin, J.; Li, J.; Chen, H.; Wang, J.; Yan, P.; Liu, M.; Liu, W.; Lu, W.; Xu, Z.; Zhang, W. Large-area highly crystalline WSe 2 atomic layers for ultrafast pulsed lasers. Opt. Express 2017, 25, 30020-30031. [CrossRef] [PubMed]

118. Uddin, S.; Song, Y.-W. Atomic Carbon Spraying: Direct Growth of Graphene on Customized 3D Surfaces of Ultrafast Optical Devices. Adv. Opt. Mater. 2020, 8, 1902091. [CrossRef]

119. Kim, W.-J.; Debnath, P.C.; Lee, J.; Lee, J.H.; Lim, D.-S.; Song, Y.-W. Transfer-free synthesis of multilayer graphene using a singlestep process in an evaporator and formation confirmation by laser mode-locking. Nanotechnology 2013, 24, 365603. [CrossRef] [PubMed]

120. Debnath, P.C.; Uddin, S.; Song, Y.-W. Ultrafast all-optical switching incorporating in situ graphene grown along an optical fiber by the evanescent field of a laser. ACS Photonics 2018, 5, 445-455. [CrossRef]

121. Reina, A.; Son, H.; Jiao, L.; Fan, B.; Dresselhaus, M.S.; Liu, Z.; Kong, J. Transferring and Identification of Single- and Few-Layer Graphene on Arbitrary Substrates. J. Phys. Chem. C 2008, 112, 17741-17744. [CrossRef]

122. Song, Y.-W.; Yamashita, S.; Goh, C.S.; Set, S.Y. Carbon nanotube mode lockers with enhanced nonlinearity via evanescent field interaction in D-shaped fibers. Opt. Lett. 2007, 32, 148-150. [CrossRef]

123. Song, Y.-W.; Morimune, K.; Set, S.Y.; Yamashita, S. Polarization insensitive all-fiber mode-lockers functioned by carbon nanotubes deposited onto tapered fibers. Appl. Phys. Lett. 2007, 90, 021101. [CrossRef]

124. Zhao, J.; Ruan, S.; Yan, P.; Zhang, H.; Yu, Y.; Wei, H.; Luo, J. Cladding-filled graphene in a photonic crystal fiber as a saturable absorber and its first application for ultrafast all-fiber laser. Opt. Eng. 2013, 52, 106105. [CrossRef]

125. Lin, Y.-H.; Yang, C.-Y.; Liou, J.-H.; Yu, C.-P.; Lin, G.-R. Using graphene nano-particle embedded in photonic crystal fiber for evanescent wave mode-locking of fiber laser. Opt. Express 2013, 21, 16763-16776. [CrossRef]

126. Woodward, R.I.; Howe, R.C.T.; Runcorn, T.H.; Hu, G.; Torrisi, F.; Kelleher, E.J.R.; Hasan, T. Wideband saturable absorption in few-layer molybdenum diselenide ( $\mathrm{MoSe}_{2}$ ) for Q-switching Yb-, Er- and Tm-doped fiber lasers. Opt. Express 2015, 23, 20051-20061. [CrossRef]

127. Liu, X.M.; Yang, H.R.; Cui, Y.D.; Chen, G.W.; Yang, Y.; Wu, X.Q.; Yao, X.K.; Han, D.D.; Han, X.X.; Zeng, C.; et al. Graphene-clad microfibre saturable absorber for ultrafast fibre lasers. Sci. Rep. 2016, 6, 26024. [CrossRef]

128. Park, N.H.; Jeong, H.; Choi, S.Y.; Kim, M.H.; Rotermund, F.; Yeom, D.I. Monolayer graphene saturable absorbers with strongly enhanced evanescent-field interaction for ultrafast fiber laser mode-locking. Opt. Express 2015, 23, 19806-19812. [CrossRef]

129. Purdie, D.G.; Popa, D.; Wittwer, V.J.; Jiang, Z.; Bonacchini, G.; Torrisi, F.; Milana, S.; Lidorikis, E.; Ferrari, A.C. Few-cycle pulses from a graphene mode-locked all-fiber laser. Appl. Phys. Lett. 2015, 106, 253101. [CrossRef]

130. Choi, S.Y.; Jeong, H.; Hong, B.H.; Rotermund, F.; Yeom, D.-I. All-fiber dissipative soliton laser with 10.2 nJ pulse energy using an evanescent field interaction with graphene saturable absorber. Laser Phys. Lett. 2013, 11, 015101. [CrossRef] 
131. Sotor, J.; Sobon, G.; Abramski, K.M. Sub-130 fs mode-locked Er-doped fiber laser based on topological insulator. Opt. Express 2014, 22, 13244-13249. [CrossRef]

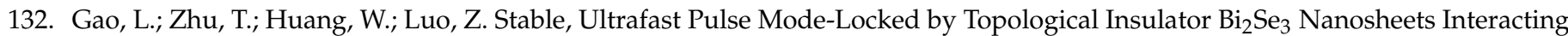
With Photonic Crystal Fiber: From Anomalous Dispersion to Normal Dispersion. IEEE Photonics J. 2015, 7, 1-8.

133. Liu, W.; Pang, L.; Han, H.; Liu, M.; Lei, M.; Fang, S.; Teng, H.; Wei, Z. Tungsten disulfide saturable absorbers for 67 fs mode-locked erbium-doped fiber lasers. Opt. Express 2017, 25, 2950-2959. [CrossRef]

134. Wang, J.; Jiang, Z.; Chen, H.; Li, J.; Yin, J.; Wang, J.; He, T.; Yan, P.; Ruan, S. High energy soliton pulse generation by a magnetron-sputtering-deposition-grown $\mathrm{MoTe}_{2}$ saturable absorber. Photonics Res. 2018, 6, 535-541. [CrossRef]

135. Jin, X.; Hu, G.; Zhang, M.; Hu, Y.; Albrow-Owen, T.; Howe, R.C.T.; Wu, T.C.; Wu, Q.; Zheng, Z.; Hasan, T. 102 fs pulse generation from a long-term stable, inkjet-printed black phosphorus-mode-locked fiber laser. Opt. Express 2018, 26, 12506-12513. [CrossRef]

136. Kim, D.; Park, N.H.; Lee, H.; Lee, J.; Yeom, D.-I.; Kim, J. Graphene-based saturable absorber and mode-locked laser behaviors under gamma-ray radiation. Photonics Res. 2019, 7, 742-747. [CrossRef]

137. Bao, Q.; Zhang, H.; Ni, Z.; Wang, Y.; Polavarapu, L.; Shen, Z.; Xu, Q.-H.; Tang, D.; Loh, K.P. Monolayer graphene as a saturable absorber in a mode-locked laser. Nano Res. 2011, 4, 297-307. [CrossRef]

138. Los, J.H.; Zakharchenko, K.V.; Katsnelson, M.I.; Fasolino, A. Melting temperature of graphene. Phys. Rev. B 2015, $91,045415$. [CrossRef]

139. Huang, P.L.; Lin, S.C.; Yeh, C.Y.; Kuo, H.H.; Huang, S.H.; Lin, G.R.; Li, L.J.; Su, C.Y.; Cheng, W.H. Stable mode-locked fiber laser based on CVD fabricated graphene saturable absorber. Opt. Express 2012, 20, 2460-2465. [CrossRef]

140. Martinez, A.; Fuse, K.; Yamashita, S. Mechanical exfoliation of graphene for the passive mode-locking of fiber lasers. Appl. Phys. Lett. 2011, 99, 121107. [CrossRef]

141. Sobon, G.; Sotor, J.; Abramski, K. All-polarization maintaining femtosecond Er-doped fiber laser mode-locked by graphene saturable absorber. Laser Phys. Lett. 2012, 9, 581. [CrossRef]

142. Sotor, J.; Pasternak, I.; Krajewska, A.; Strupinski, W.; Sobon, G. Sub-90 fs a stretched-pulse mode-locked fiber laser based on a graphene saturable absorber. Opt. Express 2015, 23, 27503-27508. [CrossRef]

143. Sun, Z.; Popa, D.; Hasan, T.; Torrisi, F.; Wang, F.; Kelleher, E.J.; Travers, J.C.; Nicolosi, V.; Ferrari, A.C. A stable, wideband tunable, near transform-limited, graphene-mode-locked, ultrafast laser. Nano Res. 2010, 3, 653-660. [CrossRef]

144. Zhou, Y.; Lin, J.; Zhang, X.; Xu, L.; Gu, C.; Sun, B.; Wang, A.; Zhan, Q. Self-starting passively mode-locked all fiber laser based on carbon nanotubes with radially polarized emission. Photonics Res. 2016, 4, 327-330. [CrossRef]

145. Wu, K.; Li, X.; Wang, Y.; Wang, Q.J.; Shum, P.P.; Chen, J. Towards low timing phase noise operation in fiber lasers mode locked by graphene oxide and carbon nanotubes at $1.5 \mu \mathrm{m}$. Opt. Express 2015, 23, 501-511. [CrossRef]

146. Lau, K.Y.; Ker, P.J.; Abas, A.F.; Alresheedi, M.T.; Mahdi, M.A. Mode-locked fiber laser in the C-band region for dual-wavelength ultrashort pulses emission using a carbon nanotube saturable absorber. Chin. Opt. Lett. 2019, 17, 051401. [CrossRef]

147. Yemineni, S.R.; Arokiaswami, A.; Shum, P. All-fiber femtosecond laser pulse generation at $1.55 \mu \mathrm{m}$ and $2 \mu \mathrm{m}$ using a common carbon-nanotube based saturable absorber. In Proceedings of the 2017 IEEE Conference on Lasers and Electro-Optics Pacific Rim (CLEO-PR), Singapore, 31 July-4 August 2017; pp. 1-2.

148. Lazarev, V.; Krylov, A.; Dvoretskiy, D.; Sazonkin, S.; Pnev, A.; Leonov, S.; Shelestov, D.; Tarabrin, M.; Karasik, V.; Kireev, A. Stable similariton generation in an all-fiber hybrid mode-locked ring laser for frequency metrology. IEEE Trans. Ultrason. Ferroelectr. Freq. Control. 2016, 63, 1028-1033. [CrossRef]

149. Chen, Y.; Chen, S.; Liu, J.; Gao, Y.; Zhang, W. Sub-300 femtosecond soliton tunable fiber laser with all-anomalous dispersion passively mode locked by black phosphorus. Opt. Express 2016, 24, 13316-13324. [CrossRef]

150. Jin, X.; Hu, G.; Zhang, M.; Hu, Y.; Albrow-Owen, T.; Howe, R.; Wu, T.; Zhu, X.; Zheng, Z.; Hasan, T. Long term stable black phosphorus saturable absorber for mode-locked fiber laser. In Proceedings of the 2017 Conference on Lasers and Electro-Optics (CLEO): Science and Innovations, Optical Society of America, San Jose, CA, USA, 14-19 May 2017; p. SW4K. 1.

151. Liu, M.; Zhao, N.; Liu, H.; Zheng, X.-W.; Luo, A.-P.; Luo, Z.-C.; Xu, W.-C.; Zhao, C.-J.; Zhang, H.; Wen, S.-C. Dual-wavelength harmonically mode-locked fiber laser with topological insulator saturable absorber. IEEE Photonics Technol. Lett. 2014, 26, 983-986.

152. Li, K.; Song, Y.; Yu, Z.; Xu, R.; Dou, Z.; Tian, J. L-band femtosecond fibre laser based on $\mathrm{Bi}_{2} \mathrm{Se}_{3}$ topological insulator. Laser Phys. Lett. 2015, 12, 105103. [CrossRef]

153. Haris, H.; Arof, H.; Muhammad, A.R.; Anyi, C.L.; Tan, S.J.; Kasim, N.; Harun, S.W. Passively Q-switched and mode-locked Erbium-doped fiber laser with topological insulator Bismuth Selenide $\left(\mathrm{Bi}_{2} \mathrm{Se}_{3}\right)$ as saturable absorber at C-band region. Opt. Fiber Technol. 2019, 48, 117-122. [CrossRef]

154. Guo, Q.; Pan, J.; Liu, Y.; Si, H.; Lu, Z.; Han, X.; Gao, J.; Zuo, Z.; Zhang, H.; Jiang, S. Output energy enhancement in a mode-locked Er-doped fiber laser using CVD-Bi ${ }_{2} \mathrm{Se}_{3}$ as a saturable absorber. Opt. Express 2019, 27, 24670-24681. [CrossRef]

155. Lin, Y.-H.; Yang, C.-Y.; Lin, S.-F.; Tseng, W.-H.; Bao, Q.; Wu, C.-I.; Lin, G.-R. Soliton compression of the erbium-doped fiber laser weakly started mode-locking by nanoscale p-type $\mathrm{Bi}_{2} \mathrm{Te}_{3}$ topological insulator particles. Laser Phys. Lett. 2014, $11,055107$. [CrossRef]

156. Lee, J.; Koo, J.; Lee, J.H. A pulse-width-tunable, mode-locked fiber laser based on dissipative soliton resonance using a bulkstructured $\mathrm{Bi}_{2} \mathrm{Te}_{3}$ topological insulator. Opt. Eng. 2016, 55, 081309. [CrossRef]

157. Luo, Z.-C.; Liu, M.; Liu, H.; Zheng, X.-W.; Luo, A.-P.; Zhao, C.-J.; Zhang, H.; Wen, S.-C.; Xu, W.-C. 2 GHz passively harmonic mode-locked fiber laser by a microfiber-based topological insulator saturable absorber. Opt. Lett. 2013, 38, 5212-5215. [CrossRef] 
158. Wei, Q.; Niu, K.; Han, X.; Zhang, H.; Zhang, C.; Yang, C.; Man, B. Large energy pulses generation in a mode-locked Er-doped fiber laser based on CVD-grown $\mathrm{Bi}_{2} \mathrm{Te}_{3}$ saturable absorber. Opt. Mater. Express 2019, 9, 3535-3545. [CrossRef]

159. Yan, P.; Lin, R.; Ruan, S.; Liu, A.; Chen, H.; Zheng, Y.; Chen, S.; Guo, C.; Hu, J. A practical topological insulator saturable absorber for mode-locked fiber laser. Sci. Rep. 2015, 5, 1-5. [CrossRef]

160. Liu, C.; Li, H.; Deng, G.; Lan, C.; Li, C.; Liu, Y. Femtosecond Er-Doped Fiber Laser Using a Graphene/MoS ${ }_{2}$ Heterostructure Saturable Absorber. In Proceedings of the 2016 Asia Communications and Photonics Conference (ACP), Wuhan, China, 2-5 November 2016; pp. 1-3.

161. Ahmed, M.; Latiff, A.; Arof, H.; Harun, S.W. Mode-locking pulse generation with $\mathrm{MoS}_{2}-\mathrm{PVA}$ saturable absorber in both anomalous and ultra-long normal dispersion regimes. Appl. Opt. 2016, 55, 4247-4252. [CrossRef] [PubMed]

162. Khazaeizhad, R.; Kassani, S.H.; Jeong, H.; Yeom, D.I.; Oh, K. Mode-locking of Er-doped fiber laser using a multilayer MoS 2 thin film as a saturable absorber in both anomalous and normal dispersion regimes. Opt. Express 2014, 22, 23732-23742. [CrossRef] [PubMed]

163. Liu, M.; Zheng, X.-W.; Qi, Y.-L.; Liu, H.; Luo, A.-P.; Luo, Z.-C.; Xu, W.-C.; Zhao, C.-J.; Zhang, H. Microfiber-based few-layer MoS 2 saturable absorber for $2.5 \mathrm{GHz}$ passively harmonic mode-locked fiber laser. Opt. Express 2014, 22, 22841-22846. [CrossRef]

164. Liu, H.; Luo, A.-P.; Wang, F.-Z.; Tang, R.; Liu, M.; Luo, Z.-C.; Xu, W.-C.; Zhao, C.-J.; Zhang, H. Femtosecond pulse erbium-doped fiber laser by a few-layer $\mathrm{MoS}_{2}$ saturable absorber. Opt. Lett. 2014, 39, 4591-4594. [CrossRef]

165. Wu, K.; Zhang, X.; Wang, J.; Chen, J. 463-MHz fundamental mode-locked fiber laser based on few-layer MoS 2 saturable absorber. Opt. Lett. 2015, 40, 1374-1377. [CrossRef]

166. Wang, Y.; Mao, D.; Gan, X.; Han, L.; Ma, C.; Xi, T.; Zhang, Y.; Shang, W.; Hua, S.; Zhao, J. Harmonic mode locking of bound-state solitons fiber laser based on $\mathrm{MoS}_{2}$ saturable absorber. Opt. Express 2015, 23, 205-210. [CrossRef]

167. Koo, J.; Park, J.; Lee, J.; Jhon, Y.M.; Lee, J.H. Femtosecond harmonic mode-locking of a fiber laser at 3.27 GHz using a bulk-like, $\mathrm{MoSe}_{2}$-based saturable absorber. Opt. Express 2016, 24, 10575-10589. [CrossRef] [PubMed]

168. Ahmad, H.B.; Aidit, S.N.; Hassan, N.A.; Ismail, M.F.; Tiu, Z.C. Generation of mode-locked erbium-doped fiber laser using MoSe 2 as saturable absorber. Opt. Eng. 2016, 55, 076115. [CrossRef]

169. Liu, W.; Liu, M.; OuYang, Y.; Hou, H.; Lei, M.; Wei, Z. CVD-grown MoSe 2 with high modulation depth for ultrafast mode-locked erbium-doped fiber laser. Nanotechnology 2018, 29, 394002. [CrossRef] [PubMed]

170. Zhang, R.-L.; Wang, J.; Zhang, X.-Y.; Lin, J.-T.; Li, X.; Kuan, P.-W.; Zhou, Y.; Liao, M.-S.; Gao, W.-Q. Mode-locked fiber laser with $\mathrm{MoSe}_{2}$ saturable absorber based on evanescent field. Chin. Phys. B 2019, 28, 014207. [CrossRef]

171. Liu, M.; Liu, W.; Wei, Z. MoTe 2 saturable absorber with high modulation depth for erbium-doped fiber laser. J. Lightwave Technol. 2019, 37, 3100-3105. [CrossRef]

172. Han, X. 2D MoTe 2 film as a saturable absorber for a wavelength-tunable ultrafast fiber laser. Appl. Opt. 2019, 58, 8390-8395. [CrossRef]

173. Khazaeinezhad, R.; Kassani, S.H.; Jeong, H.; Yeom, D.-I.; Oh, K. Femtosecond soliton pulse generation using evanescent field interaction through Tungsten disulfide $\left(\mathrm{WS}_{2}\right)$ film. J. Lightwave Technol. 2015, 33, 3550-3557. [CrossRef]

174. Wu, K.; Zhang, X.; Wang, J.; Li, X.; Chen, J. WS ${ }_{2}$ as a saturable absorber for ultrafast photonic applications of mode-locked and Q-switched lasers. Opt. Express 2015, 23, 11453-11461. [CrossRef]

175. Mao, D.; Zhang, S.; Wang, Y.; Gan, X.; Zhang, W.; Mei, T.; Wang, Y.; Wang, Y.; Zeng, H.; Zhao, J. WS 2 saturable absorber for dissipative soliton mode locking at 1.06 and $1.55 \mu \mathrm{m}$. Opt. Express 2015, 23, 27509-27519. [CrossRef]

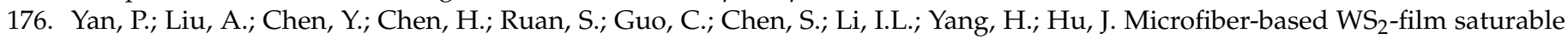
absorber for ultra-fast photonics. Opt. Mater. Express 2015, 5, 479-489. [CrossRef]

177. Yan, P.; Liu, A.; Chen, Y.; Wang, J.; Ruan, S.; Chen, H.; Ding, J. Passively mode-locked fiber laser by a cell-type WS 2 nanosheets saturable absorber. Sci. Rep. 2015, 5, 1-7. [CrossRef] [PubMed]

178. Koo, J.; Jhon, Y.I.; Park, J.; Lee, J.; Jhon, Y.M.; Lee, J.H. Near-Infrared saturable absorption of defective bulk-structured WTe 2 for femtosecond laser mode-locking. Adv. Funct. Mater. 2016, 26, 7454-7461. [CrossRef]

179. Wu, Q.; Zhang, M.; Jin, X.; Chen, S.; Jiang, Q.; Jiang, X.; Zheng, Z.; Zhang, H. 104 fs mode-locked fiber laser with a MXene-based saturable absorber. In Proceedings of the 2019 Conference on Lasers and Electro-Optics (CLEO): Applications and Technology, Optical Society of America, San Jose, CA, USA, 5-10 May 2019; p. JW2A. 86.

180. Jiang, X.; Liu, S.; Liang, W.; Luo, S.; He, Z.; Ge, Y.; Wang, H.; Cao, R.; Zhang, F.; Wen, Q. Broadband nonlinear photonics in few-layer MXene $\mathrm{Ti}_{3} \mathrm{C}_{2} \mathrm{~T}_{\mathrm{x}}(\mathrm{T}=\mathrm{F}, \mathrm{O}$, or $\mathrm{OH})$. Laser Photonics Rev. 2018, 12, 1700229. [CrossRef]

181. Yi, J.; Du, L.; Li, J.; Yang, L.; Hu, L.; Huang, S.; Dong, Y.; Miao, L.; Wen, S.; Mochalin, V.N. Unleashing the potential of Ti ${ }_{2} \mathrm{CT}_{\mathrm{x}}$ MXene as a pulse modulator for mid-infrared fiber lasers. 2D Mater. 2019, 6, 045038. [CrossRef]

182. Du, J.; Zhang, M.; Zhu, X.; Hu, G.; Zhao, X.; Zheng, Z.; Zhang, H. Microfiber-based few-layer black phosphorus quantum dots saturable absorber for mode-locked fiber laser. In Proceedings of the 2016 IEEE Conference on Lasers and Electro-Optics (CLEO), San Jose, CA, USA, 5-10 June 2016; pp. 1-2.

183. Set, S.Y.; Yaguchi, H.; Tanaka, Y.; Jablonski, M.; Sakakibara, Y.; Rozhin, A.; Tokumoto, M.; Kataura, H.; Achiba, Y.; Kikuchi, K. Mode-locked Fiber Lasers based on a Saturable Absorber Incorporating Carbon Nanotubes. In Proceedings of the Optical Fiber Communication Conference, Atlanta, Georgia, 23 March 2003; p. PD44.

184. Martinez, A.; Al Araimi, M.; Dmitriev, A.; Lutsyk, P.; Li, S.; Mou, C.; Rozhin, A.; Sumetsky, M.; Turitsyn, S. Low-loss saturable absorbers based on tapered fibers embedded in carbon nanotube/polymer composites. APL Photonics 2017, 2, 126103. [CrossRef] 
185. Martinez, A.; Zhou, K.; Bennion, I.; Yamashita, S. In-fiber microchannel device filled with a carbon nanotube dispersion for passive mode-lock lasing. Opt. Express 2008, 16, 15425-15430. [CrossRef]

186. Martinez, A.; Zhou, K.; Bennion, I.; Yamashita, S. Passive mode-locked lasing by injecting a carbon nanotube-solution in the core of an optical fiber. Opt. Express 2010, 18, 11008-11014. [CrossRef]

187. Li, Y.; Gao, L.; Huang, W.; Gao, C.; Liu, M.; Zhu, T. All-fiber mode-locked laser via short single-wall carbon nanotubes interacting with evanescent wave in photonic crystal fiber. Opt. Express 2016, 24, 23450-23458. [CrossRef]

188. Choi, S.Y.; Rotermund, F.; Jung, H.; Oh, K.; Yeom, D.I. Femtosecond mode-locked fiber laser employing a hollow optical fiber filled with carbon nanotube dispersion as saturable absorber. Opt. Express 2009, 17, 21788-21793. [CrossRef]

189. Hisyam, M.B.; Rusdi, M.F.M.; Latiff, A.A.; Harun, S.W. Generation of mode-locked ytterbium doped fiber ring laser using few-layer black phosphorus as a saturable absorber. IEEE J. Sel. Top. Quantum Electron. 2016, 23, 39-43. [CrossRef]

190. Pawliszewska, M.; Ge, Y.; Li, Z.; Zhang, H.; Sotor, J. Fundamental and harmonic mode-locking at 2.1 mm with black phosphorus saturable absorber. Opt. Express 2017, 25, 16916-16921. [CrossRef]

191. Lu, L.; Liang, Z.; Wu, L.; Chen, Y.; Song, Y.; Dhanabalan, S.C.; Ponraj, J.S.; Dong, B.; Xiang, Y.; Xing, F.; et al. Few-layer Bismuthene: Sonochemical Exfoliation, Nonlinear Optics and Applications for Ultrafast Photonics with Enhanced Stability. Laser Photonics Rev. 2018, 12, 1700221. [CrossRef]

192. Island, J.O.; Steele, G.A.; van der Zant, H.S.; Castellanos-Gomez, A. Environmental instability of few-layer black phosphorus. 2D Mater. 2015, 2, 011002. [CrossRef]

193. Zhang, Y.; Yu, H.; Zhang, R.; Zhao, G.; Zhang, H.; Chen, Y.; Mei, L.; Tonelli, M.; Wang, J. Broadband atomic-layer MoS 2 optical modulators for ultrafast pulse generations in the visible range. Opt. Lett. 2017, 42, 547-550. [CrossRef] [PubMed]

194. Wang, S.; Yu, H.; Zhang, H.; Wang, A.; Zhao, M.; Chen, Y.; Mei, L.; Wang, J. Broadband Few-Layer MoS 2 Saturable Absorbers. Adv. Mater. 2014, 26, 3538-3544. [CrossRef] [PubMed]

195. Khazaeinezhad, R.; Kassani, S.H.; Jeong, H.; Park, K.J.; Kim, B.Y.; Yeom, D.-I.; Oh, K. Ultrafast pulsed all-fiber laser based on tapered fiber enclosed by few-layer $\mathrm{WS}_{2}$ nanosheets. IEEE Photonics Technol. Lett. 2015, 27, 1581-1584. [CrossRef]

196. Wang, K.; Wang, J.; Fan, J.; Lotya, M.; O’Neill, A.; Fox, D.; Feng, Y.; Zhang, X.; Jiang, B.; Zhao, Q.; et al. Ultrafast Saturable Absorption of Two-Dimensional $\mathrm{MoS}_{2}$ Nanosheets. ACS Nano 2013, 7, 9260-9267. [CrossRef]

197. Zhang, H.; Lu, S.B.; Zheng, J.; Du, J.; Wen, S.C.; Tang, D.Y.; Loh, K.P. Molybdenum disulfide $\left(\mathrm{MoS}_{2}\right)$ as a broadband saturable absorber for ultra-fast photonics. Opt. Express 2014, 22, 7249-7260. [CrossRef]

198. Manzeli, S.; Ovchinnikov, D.; Pasquier, D.; Yazyev, O.V.; Kis, A. 2D transition metal dichalcogenides. Nat. Rev. Mater. 2017, 2, 17033. [CrossRef]

199. Ouyang, Q.; Yu, H.; Zhang, K.; Chen, Y. Saturable absorption and the changeover from saturable absorption to reverse saturable absorption of $\mathrm{MoS}_{2}$ nanoflake array films. J. Mater. Chem. C 2014, 2, 6319-6325. [CrossRef]

200. Xia, H.; Li, H.; Lan, C.; Li, C.; Zhang, X.; Zhang, S.; Liu, Y. Ultrafast erbium-doped fiber laser mode-locked by a CVD-grown molybdenum disulfide $\left(\mathrm{MoS}_{2}\right)$ saturable absorber. Opt. Express 2014, 22, 17341-17348. [CrossRef] [PubMed]

201. Zhao, C.; Zhang, H.; Qi, X.; Chen, Y.; Wang, Z.; Wen, S.; Tang, D. Ultra-short pulse generation by a topological insulator based saturable absorber. Appl. Phys. Lett. 2012, 101, 211106. [CrossRef]

202. Chen, S.; Zhao, C.; Li, Y.; Huang, H.; Lu, S.; Zhang, H.; Wen, S. Broadband optical and microwave nonlinear response in topological insulator. Opt. Mater. Express 2014, 4, 587-596. [CrossRef]

203. Yu, H.; Zhang, H.; Wang, Y.; Zhao, C.; Wang, B.; Wen, S.; Zhang, H.; Wang, J. Topological insulator as an optical modulator for pulsed solid-state lasers. Laser Photonics Rev. 2013, 7, L77-L83. [CrossRef]

204. Dou, Z.; Song, Y.; Tian, J.; Liu, J.; Yu, Z.; Fang, X. Mode-locked ytterbium-doped fiber laser based on topological insulator: Bi ${ }_{2} \mathrm{Se}_{3}$. Opt. Express 2014, 22, 24055-24061. [CrossRef] [PubMed]

205. Zhao, C.; Zou, Y.; Chen, Y.; Wang, Z.; Lu, S.; Zhang, H.; Wen, S.; Tang, D. Wavelength-tunable picosecond soliton fiber laser with Topological Insulator: $\mathrm{Bi}_{2} \mathrm{Se}_{3}$ as a mode locker. Opt. Express 2012, 20, 27888-27895. [CrossRef] [PubMed]

206. Li, W.; Chen, B.; Meng, C.; Fang, W.; Xiao, Y.; Li, X.; Hu, Z.; Xu, Y.; Tong, L.; Wang, H.; et al. Ultrafast All-Optical Graphene Modulator. Nano Lett. 2014, 14, 955-959. [CrossRef]

207. Sheng, Q.-W.; Feng, M.; Xin, W.; Guo, H.; Han, T.-Y.; Li, Y.-G.; Liu, Y.-G.; Gao, F.; Song, F.; Liu, Z.-B.; et al. Tunable graphene saturable absorber with cross absorption modulation for mode-locking in fiber laser. Appl. Phys. Lett. 2014, 105, 041901. [CrossRef]

208. Girard, S.; Morana, A.; Ladaci, A.; Robin, T.; Mescia, L.; Bonnefois, J.-J.; Boutillier, M.; Mekki, J.; Paveau, A.; Cadier, B. Recent advances in radiation-hardened fiber-based technologies for space applications. J. Opt. 2018, 20, 093001. [CrossRef]

209. Fortescue, P.; Swinerd, G.; Stark, J. Spacecraft Systems Engineering, 4th ed.; John Wiley \& Sons: Hoboken, NJ, USA, $2011 ;$ p. 399. 